\title{
El concejo imparte justicia: cotos de los oficiales locales a mediados del siglo $\mathrm{XV}^{*}$
}

\author{
The council administers justice: the salaries of local officials \\ arond the middle of the XV century
}

José Miguel LÓPEZ VilLALBA**

\begin{abstract}
RESUMEN
En la Plena Edad Media el Derecho se convirtió progresivamente en la llave de la resolución de todos los asuntos conflictivos. El rey fue adquiriendo una serie de prerrogativas sobre la aplicación de la justicia llegando a concretar

derechos y deberes con los gobiernos locales, a la vez que les fue cercando con una mayor intervención por medio de los oficios concejiles. Surgieron de este modo una serie de oficiales que asumiendo diferentes actuaciones se ocuparon, entre otras, de las labores jurisdiccionales de los ayuntamientos. De entre ellos destacan, ya en la Baja Edad Media, corregidores, alcaldes, jurados, alguaciles y escribanos, que marcaron el compás de dichas

funciones municipales de justicia. Las formas de estipendio que recibían estos oficiales por su responsabilidad se resumían en el binomio salario-arancel, sistema propio de muchos de los oficios públicos medievales. No resulta sencillo

ponderar qué cantidad de lo recibido correspondería a cada una de las formas
\end{abstract}

\begin{abstract}
In the Early Middle Ages Law gradually became the key to solving every conflict. The king started to accumulate a series of prerogatives in the administration of justice and reached agreements with local authorities while he gained more and more control through council jobs. This accounts for the appearance of a group of officials who took on-among others-the legal duties to be dealt with in borough councils. In this respect, special attention must be paid to 'corregidores', mayors, members of the jury, sheriffs and scribes. These officials were paid on a salary-tariff basis, which was common in most borough council jobs in the Middle Ages. It is not easy to know how their final income was worked out. The 'corregidor's salary was taken from the council coffers, just like that of the other borough council officials who performed similar administrative duties. This paper deals with the legal duties the borough council officials carried out and the salary they received in Guadalajara in the $X V$ century.
\end{abstract}

* Fecha de recepción del artículo: 2010-1-11. Fecha de aceptación del artículo: 2010-2-15.

** Departamento de Historia Medieval y Ciencias y Técnicas Historiográficas. UNED. C.e.: jlopez@geo.uned.es. 
de obtención del pago. El corregidor como el resto de los oficiales municipales de justicia recaudaba sus honorarios de las arcas municipales. En este trabajo se estudian las funciones judiciales y las tasas correspondientes percibidas por los oficiales del concejo de Guadalajara durante mediados del siglo XV.

PALABRAS CLAVE

Derecho local; concejos; oficiales concejiles; Castilla; Baja Edad Media.
KEY WORDS:

Local Law; councils; council officials; Castille; Late Middle Ages.

\section{INTRODUCCIÓN}

La Plena Edad Media, además de estar poco organizada jurisdiccionalmente, asistió en sus comienzos a un primitivismo social propio de unas comunidades que conservaban escasos restos de la pasada romanización. Por ello, en un periodo anterior, que se podría fechar entre los siglos VIII y X, se mantuvo una concepción fuertemente arraigada en las formas más elementales de la justicia privada para la resolución de los asuntos civiles y criminales. Pronto, desde los poderes fácticos, se crearon las condiciones y los instrumentos necesarios para que la actuación judicial llegase a ser una de las funciones más características del poder real. El rey fue adquiriendo una serie de cometidos referentes a la aplicación de la justicia que lentamente se van haciendo mayores hasta transformarse en una gestión suprema por encima del resto de las autoridades terrenales.

Ello sin olvidar que, en un primer momento, el Derecho se convierte de este modo y progresivamente en la llave de la resolución de todos los asuntos conflictivos por medio del empleo, por un lado de la repetición del desenlace y en ello residía la primacía que adquirió el uso y la costumbre; y por otro, en la utilización habitual de los flecos del Derecho romano. Las nuevas leyes, producto de un empeño y una frescura meritorios, cada día intentaban solventar con diversos procedimientos los asuntos generados por las competencias nacientes que, aún sin definir claramente, se enredaban como una red difícil de sortear y que prontamente habría que precisar para avanzar en los postulados y en las soluciones. La monarquía tomó en sus manos el desentrañamiento de dicha urdimbre y, como consecuencia, el control de muchas de las cuestiones que durante tantos años ocuparon una posición de autonomía fueron invadidas por la condición sobresaliente de la justicia regia. En un somero repaso, se han de destacar, siguiendo los postulados de Torres Sanz: la defensa de la Religión y de la Iglesia; la administración de la justicia civil y penal buscando resolver, ante todo, las contravenciones en el orden social; la importantísima concesión de mercedes y privilegios; la defensa de 
las propiedades de los súbditos ante el peligro exterior, referido con toda seguridad a los enemigos de la Iglesia y de la $\mathrm{Fe}$, que se presentaron como uno de los motivos de discordia bélica a lo largo del medievo castellano; pero igualmente asegurar la protección contra la discordia interior, es decir, contra los que alteraban el orden establecido dentro del reino. Todo ello desde la visión del Derecho como un todo inseparable del orden social, que tanto se defiende en los anteriores aspectos y que emana del transcurrir de la actuación de la colectividad. Finalmente, aparecen los atributos más indispensables en la concepción de una justicia poco definida, tales como la piedad o la misericordia ${ }^{1}$.

Otro de los aspectos más característicos de la evolución y expansión de la justicia a lo largo de los estados emergentes, fue la jurisdicción señorial. Un progreso en el gobierno de los señores que fueron sumando a sus numerosos privilegios el de la inmunidad, que en la práctica les permitió llevar a cabo la aplicación de la estructura judicial en los señoríos. Pero, no se debe olvidar que tanto esta función como el resto de los aprovechamientos y prerrogativas de los que disfrutaban dichos títulos respondían a donaciones reales ${ }^{2}$. El poder real planeaba por encima de cualquiera de los súbditos de la escala social, política o económica, por todo ello, aun dejando fuera la explicación de muchos aspectos que no corresponden a estas páginas, fue gestándose un procedimiento que acabaría con la aparición de un mayor poder para la Corona de control de las poblaciones. Así, Alfonso $X^{3}$, apoyado en la expansión del Fuero Real a partir de 1255, dejó plenamente diseñado un camino para avanzar sin tropiezos considerables en la implantación de unos principios jurídicos generales que cimentaron con el tiempo un nuevo orden político y social ${ }^{4}$.

Respecto a los municipios y la actuación de la justicia en los mismos, es conveniente puntualizar que el progreso jurídico local se ajustó a un desarrollo singular en la Península Ibérica debido a la llegada de los musulmanes. El consecuente periodo de enfrentamiento militar entre los diferentes reinos cristianos que surgieron de la debacle visigoda y los nuevos amos del territorio peninsular, para intentar recuperar con las armas lo que había supuesto el antiguo reino godo, mo-

1 Es conveniente, para una mirada amplia de la justicia medieval, conocer la sistematización de esta clasificación que sobre los diversos procedimientos de aplicación de la justicia fue desarrollado por TORRES SANZ, D., en su artículo: «Teoría y práctica de la acción de gobierno en el mundo medieval castellano-leonés». Historia, Instituciones, Documentos, (1985), pp. 28-36. Más recientemente otros autores han mantenido esta teoría como principio general de distribución jurídica: CALDERÓN ORTEGA, J. M.: «La justicia en Castilla y León durante la Edad Media». En La Administración de Archivos y Bibliotecas de Castilla-La Mancha. Actas de las III Jornadas de Castilla-La Mancha sobre Investigación en Archivos. 1997. Guadalajara, 1999, Volumen I, pp. 21-39. Para un buen conocimiento de la documentación judicial en la Baja Edad Media: M.J. Sanz Fuentes y M. Calleja Puerta: «La documentación judicial en el reino de Castilla. Baja Edad Media», en G. Nicolaj (ed.): La Diplomatica dei documenti giudiziari (dai placiti agli acta - secc. XII-XV), Roma, 2004, pp. 113-136.

2 En el conocimiento de los señoríos sigue siendo de referencia obligada las obras de Salvador de Moxó. Se puede destacar: «Los señoríos: cuestiones metodológicas que plantea su estudio» Anuario de Historia del Derecho Español, XLIII (1973), pp. 271-309.

3 IGLESIA FERREIROS, A.: «La obra legislativa de Alfonso X el Sabio». En España y Europa. Un pasado histórico común. Murcia, 1986, p. 292.

4 CALDERÓN ORTEGA, op. cit, p. 28. 
tivó un natural procedimiento de repoblación de la mayor parte de las tierras deshabitadas tras la invasión y el consiguiente retroceso ${ }^{5}$. El intento de recuperación cristiano iba acompañado de la ocupación de las superficies abandonadas en tierra de nadie y tras la consecuente anexión o reconquista se procedía a la consiguiente creación de municipios nuevos y la rehabilitación de los pre-existentes. Para la Corona, poder restaurar una mínima organización institucional desde la disposición generalista resultaba poco menos que imposible debido a la complicada dispersión de los poblamientos. Qué duda cabe que estos vecindarios eran la primera piedra para levantar la gran obra de un estado nuevo y que su regulación se debía realizar a través de unos elementos sencillos y autónomos, pero que sirviesen para organizar la vida vecinal y que solucionaran los problemas subyacentes, en definitiva, que permitiesen la continuidad del poblamiento como ente socialmente organizado.

La recepción del derecho local pasó, al menos, por tres periodos que se manifestaron consecutivamente. En primer lugar, se asiste a un proceso que se encuadró dentro del renacimiento de los centros de población en el seno de los poderes señorial y real y cuyos documentos representativos fueron el fuero y las cartas de población. El fuero se entiende como la carta expedida por los reyes y, en su caso, por algunos señores, en virtud del privilegio derivado de la soberanía, por medio del cual se manifiestan un conjunto de normas destinadas al buen gobierno de las villas y ciudades. Los ritmos que frecuenta el derecho local resultante de los aspectos comunes se pueden apreciar simultáneamente en todas las zonas de la repoblación, de tal suerte que los fueros ya experimentados en algunos lugares son literalmente dispuestos para muchas de las poblaciones emergentes, formándose las familias de fueros ${ }^{6}$. Dichos fueros pueden ser al menos de dos tipos: breves y extensos, siendo los segundos, en muchos casos, de carácter totalmente novedoso y no una ampliación de los primeros, como podría suponerse ${ }^{7}$.

A continuación, se advierte la existencia de un periodo de transición, fundamentado, tal vez, en un proceso de estabilidad general aparentemente perdurable, durante el cual la Corona puso en marcha sus primeros intentos de control, algunos de los cuales no consiguieron sus frutos. A comienzos del siglo XIII, Fernando III se presenta como pionero activo de la intervención real, por medio de la publicación de una norma general que trataba de impedir la extensión de ciertos malos usos en las localidades que iba recuperando en los territorios al sur y sureste pe-

\footnotetext{
5 Julio González llamó a la despoblación producida por la invasión de los musulmanes: «el quebranto de los poblados»; pero a la vez expresó su convencimiento de que no fue tan grave, porque no existe una constancia clara acerca de una Península lbérica hispano-visigoda densamente poblada. GONZÁLEZ, J.: Repoblación de Castilla la Nueva. Madrid. Universidad Complutense de Madrid. 1975. 2 Vols.

6 BARRERO GARCÍA, A. M. ${ }^{a}$, y ALONSO MARTíN, M. ${ }^{a}$ L.: Textos de derecho local español en la Edad Media. Catálogo de fueros y costums municipales. Madrid. CSIC. 1989.

7 De igual forma existen ocasiones, tal como sucede en el caso de Uclés, en las que el fuero breve se intercalaba íntegramente a modo de capítulo en la posterior normativa. Entre otros análisis destaca GARCÍA ULECIA, Alberto.: «Los factores de diferenciación entre las personas en los Fueros de la extremadura castellano-aragonesa». Anales de la Universidad Hispalense. Sevilla, (1975), p. 399.
} 
ninsular, en lo que parece un notorio intento de cercenamiento de la autonomía local por medio de la regulación de sus procedimientos políticos y sus hábitos sociales. Por su parte, Alfonso X intentará dar un paso más firme con la promulgación de diferentes medidas, tales como el Fuero Real, el Espéculo y el Libro de las Siete Partidas que serán futuro modelo de legislación. En el fondo, la reforma alfonsina al proclamar que el Rey es el único facultado para crear Derecho, tal como ya habían intentado sus antecesores, buscaba, entre otras cuestiones, el cambio en el estatuto de los señores y de los concejos. Los propios municipios atados de manos colaboraron involuntariamente, al solicitar la aprobación de nuevas normas que mejorasen su legislación y de este modo asistieron impotentes a la actividad intervencionista regia que desembocará en la normativa expedida en las Cortes de Alcalá de 1348 por Alfonso $\mathrm{XI}^{8}$.

La Corona va concretando derechos y deberes con los gobiernos locales, pero a la vez les va cercando con una mayor intervención por medio de los oficiales concejiles ${ }^{9}$. Un tiempo nuevo, por lo tanto, que va preparando un interesante modelo de gobierno municipal en el que se abandonará con lentitud, pero sin posibilidad de retorno, la anterior idea del concejo abierto. Surgieron de este modo una serie de oficiales que asumiendo diferentes actuaciones se ocuparon de los oficios administrativos, profesionales y jurisdiccionales de los ayuntamientos. De entre todos ellos destacan regidores, alcaldes, jurados, alguaciles y escribanos, que marcarán el compás de las funciones municipales. Asimismo, por encima de todos ellos, emerge la figura del corregidor, como representante real supremo, cuya actuación está encaminada al recorte de las libertades municipales que se habían sedimentado en el espacio anterior y cuyo fin último es, por lo tanto, el control absoluto del gobierno local, aunque al comienzo aparezca de forma soterrada. La figura del corregidor, cuya labor debía ser el dominio del gobierno municipal por

\footnotetext{
${ }^{8}$ En un reciente artículo, Manuel González perfila el cambio llevado a cabo por la citada reforma municipal y el consiguiente cambio de rumbo adoptado por el devenir político de los municipios. De este modo divide la influencia de la citada innovación institucional en varias razones: Según la primera, «la reforma obligó a las oligarquías a pactar para conseguir un cierto grado de estabilidad en el seno de los concejos»; a continuación defiende que: «suavizadas las tensiones, a partir de este momento y de manera definitiva, las oligarquías municipales quedarán vinculadas al poder monárquico, de donde procedía su propia legitimidad, y, por último: «porque de forma legal y no por usurpación de funciones por parte de los oligarcas, la asamblea municipal o concejo pleno pierde definitivamente su razón de ser, quedando los vecinos excluidos de participar, aunque fuese simbólica y ritualmente, en las elecciones y aprobación de las decisiones adoptadas por los gobernantes, en beneficio de un grupo cerrado de regidores o cabildo, responsables sólo ante la corona que les había designado o confirmado en los cargos de gobierno». GONZÁLEZ JIMÉNEZ, M.: «La creación del derecho local y territorial andaluz. De Alfonso X a los Reyes Católicos». Initium. Revista catalana d'Història del Dret. 9, (2004), pp. 127-208.

9 Indudablemente, aún afirmando la certidumbre histórica del planteamiento formulado, no se debe ignorar que las consideraciones radicales adoptadas por ciertos autores en la propuesta de concejos abiertos como abanderados de las libertades concejiles y los posteriores concejos cerrados como símbolo del control real, no dejan de ser matizables en muchos aspectos. Algunos autores mantienen que las teorías románticas del siglo XIX, alimentadas en la dramaturgia del Siglo de Oro, fueron la interpretación de los perdedores que como siempre sirvieron de alimento y refugio de los idealistas que llegaron a idealizar tópicos de libertad para el pueblo en los tiempos anteriores a la reforma municipal de 1348 RUIZ, T.F.: Sociedad y poder en Castilla. Barcelona, 1981.
} 
medio de la completa gestión del mismo, fue clave para el desarrollo de las políticas locales en los siglos XIV y XV, pese a que no se llegará a implantar en todas las poblaciones ${ }^{10}$.

Durante este periodo se asiste a la progresiva generalización del corregidor, en las más importantes ciudades y villas de la corona de Castilla, perfilada por un extenso grupo de disposiciones que culminarán con los Capítulos para Corregidores y Jueces de Residencia del año $1500^{11}$. Acompañando la función del máximo oficial real se manifiesta la institución del regimiento que comprometía la débil situación de la intervención popular en las decisiones del cabildo, sobre todo porque los regidores tienden a constituirse asimismo como oficiales al servicio del rey, que los nombra al principio con cierta holgura temporal, aunque acabaran siendo de estabilidad vitalicia por determinación real ${ }^{12}$. Los regidores aparecen como un conjunto de oficiales políticamente incondicionales a la corona que los nombra ${ }^{13}$. Las datas más antiguas atribuidas a la instauración de este oficio pertenecen a Murcia ${ }^{14}$ y a Sevilla ${ }^{15}$;

10 Por destacar algunas de las obras más significativas se han de citar aquellas que han tratado la cuestión con carácter general y que siempre han de servir como referencia primera: BERMÚDEZ AZNAR, A.: El corregidor en Castilla durante la Baja Edad Media (1348-1474). Murcia, 1974. GONZÁLEZ ALONSO, B.: El corregidor castellano (1348-1808). Madrid, 1970. Además, siguen resultando actuales, las teorías de Lunenfeld sobre la imposibilidad logística del cumplimiento de las variadas reformas surgidas de las citadas cortes, si no se hubiese contado con agentes reales instalados en los concejos de modo permanente LUNENFELD, M.: Los corregidores de Isabel la Católica. Barcelona, 1989. Más puntualmente y sobre esta consolidación reglamentaria del corregidor y sus consecuencias es conveniente la revisión de la obra de RUIZ POVEDANO, J.M.: El primer gobierno municipal de Málaga (1489-1495). Málaga, 1991.

11 Estos llamados Capítulos son en realidad, tal como mantiene en una obra reciente Lorenzo Cadarso, un extenso conjunto de disposiciones presentado como ordenanzas que, por medio de una provisión real, se hicieron públicas y se dirigieron al colectivo interesado. Vid. LORENZO CADARSO, P. L.: Estudio diplomático de la evolución del expediente administrativo en la Edad Moderna. Badajoz. Universidad de Extremadura, 2009, p. 22.

12 Monsalvo Antón aporta datos sobre la citada reserva regia en la temporalidad del cargo que se manifiesta claramente en el nombramiento de los regidores en algunas ciudades castellanas, al menos durante los primeros momentos posteriores al ordenamiento de Alcalá de 1348. MONSALVO ANTÓN, J. M. a: «La sociedad política en los concejos castellanos de la meseta durante la época del regimiento medieval. La distribución social del poder». En Concejos y ciudades en la Edad Media hispánica. II Congreso de Estudios Medievales. (Ávila, 1990), pp. 357-413.

13 Son muy interesantes las teorías de Vicens Vives sobre la función del oficio público en la Edad Moderna como ventaja de carácter patrimonial y no tanto como función pública. VICENS VIVES, J.: Estructura administrativa estatal en los siglos XVI y XVII. Estocolmo, 1960. Se halla recopilado dentro de su Obra Dispersa. Volumen II, pp. 359-377.

${ }^{14}$ En la ciudad de Murcia, aunque ya existían precedentes de gobierno dirigido, será Alfonso XI el que instale el regimiento en 1325, siendo una de las primeras noticias que se poseen de la intervención directa del monarca. TORRES FONTES, J.: «El concejo murciano en el reinado de Alfonso XI». Anuario de Historia del Derecho Español, XXIII, (1953), p. 141.

15 El caso de Sevilla se muestra menos claro, Desde siempre se había considerado que el año 1327 marcaba el nacimiento del regimiento sevillano pero recientemente se ha apostado por adelantarlo hasta el año 1286. De cualquier forma la certeza documental se manifiesta a partir del año 1344 que es cuando por primera vez se cita a los veinticuatro regidores. De entre la bibliografía se ha de señalar: KIRSCHBERG SHENK, D.: «La reforma municipal en Sevilla: la oligarquía hispalense y la implantación del regimiento en 1286». Archivo Hispalense, 237 (1995), pp. 11-37; y TOMAS Y VALIENTE, F.: «Origen bajomedieval de la patrimonialización y la enajenación de oficios públicos en Castilla». En Actas del I Symposium de Historia de la Administración. Madrid, (1970), pp. 123-159. Manuel González Jiménez lo adelanta a 1327, aludiendo a la publicación de KIRSCHBERG SHENK, [Marcos Fernández Gómez]. El 
siendo Ciudad Rodrigo ${ }^{16}$ uno de los primeros ejemplos dentro de la Meseta castellana. Las atribuciones que presenta el cargo son tan dispares como amplio es el campo en el que se desenvuelve su actuación que discurre por un abanico de potestades que alcanzan desde la competencia en la elaboración y modificación normativa a cierta actuación judicial en grado de apelación, pasando por la vigilancia del abastecimiento y las obras públicas o cuestiones protocolarias de cualquier aspecto como la organización de los festejos del Corpus Cristi.

Aunque los sucesores de Alfonso XI no cejaron en su empeño de cercenar cada vez más las libertades municipales, no será hasta la llegada de la monarquía de los Reyes Católicos, que amparados en ideas de modernidad llegaron con el firme propósito de convertirse en una autoridad absoluta. De tal manera, el tercer periodo en la recepción del derecho local donde se dan auténticos pasos de gigante en el control de las poblaciones, se manifiesta con la llegada de los Reyes Católi$\cos y$, entre otros aspectos, con las promulgaciones llevadas a cabo en las activas cortes de Toledo de 1480. Además, claro está, del definitivo afianzamiento de los oficiales concejiles que, apoyados fuertemente desde la Corona, seguirán arañando cada vez mayores espacios de poder dentro de la estructura del gobierno municipal. Una práctica común en la Baja Edad Media que se manifiesta por medio de la entrega de oficios como sistema de retribución de servicios o compra de nuevos partidarios, para enfrentarse a las fuerzas urbanas tradicionales.

En el transcurso del sobredicho periodo de los Reyes Católicos se pueden inferir algunos aspectos determinantes en el intento de intervención de las ciudades como consecuencia de las nuevas teorías del poder, producto de la dialéctica decisiva entre los dos vértices del mismo: la monarquía y la nobleza, y que marcará el proceso durante la posterior Edad Moderna. Desde la corona se dictaban expresiones políticas que emergen de una semilla unitaria y que desdeñan, aún no muy explícitamente, todo ese poder deslavazado territorialmente que suponen los señoríos. El control de los señoríos sobre solares y poblados civiles y eclesiásticos comienza a parecer anacrónico cuando las emergentes teorías políticas generan prácticas habituales lejanas al dominio señorial de las ciudades. Si la monarquía protomoderna procuraba ganar adeptos dentro de las clases urbanas por medio de la concesión de mercedes que se refiriesen a los oficios del concejo, no tenía otra salida que hacer inoperantes a los otros poderes que secularmente habían intervenido sobre la administración de dichos ayuntamientos ${ }^{17}$. La ciudad se

concejo de Sevilla en la Edad Media (1284-1454). Organización institucional y Fuentes documentales I. Sevilla, 2002, pp. 59 y ss.

${ }_{16}$ Esta ciudad salmantina conoció la implantación de este sistema de gobierno en el año 1327, y aunque recientemente se ha retrasado su datación hasta 1345-1350, igualmente se debe entender que sigue apareciendo como uno de los casos más tempranos en ser documentados al norte del Sistema Central. BERNAL ESTÉVEZ, A.: El concejo de Ciudad Rodrigo y su tierra durante el siglo XV. Salamanca, 1989.

17 Desde siempre se ha considerado el ejemplo por excelencia sobre esta cuestión la confrontación de la reina Isabel I con Juan Rodríguez de Fonseca, obispo de Palencia, que acaba con la desposesión de este último como señor de la ciudad. Entre otras visiones sobre la cuestión se puede plantear la que 
transforma en estos momentos en un virtual campo de batalla entre los nuevos intereses de los concejos y las entidades señoriales que ven diluirse su poder acumulado ${ }^{18}$.

\section{LA JUSTICIA LOCAL DEL CONCEJO BAJOMEDIEVAL AL MUNICIPIO MODERNO: UN CAMINO HACIA EL CONTROL ABSOLUTO DE LAS POBLACIONES}

\section{Los corregidores}

Los corregidores supusieron, como se ha dicho, un verdadero acicate a la política regia en su progreso hacia el final de los procedimientos autonomistas de los municipios. Su aparición en el escenario político de las poblaciones representando la continuación de la obra de los «juizes de salario» y de los «alcaldes veedores» se produjo en las Cortes de Alcalá de Henares de 1348, cuando los procuradores de las ciudades denominan al delegado regio con la expresión: «corregidor de los pleitos de justicia» ${ }^{19}$. La figura del corregidor se reveló a lo largo del siglo XV, tal como ya se ha visto, como la del oficial real por excelencia, que además recibió en tiempo de los Reyes Católicos toda la fuerza que necesitaba desde la Corona para ayudar al establecimiento de la extensa normativa emanada en las Cortes de Toledo de 1480, gracias a la cual los monarcas perseguían el logro de sus objetivos de control definitivo sobre las poblaciones ${ }^{20}$. La actuación del corregidor supuso, como se viene insistiendo, la salvaguardia, a lo largo de todo el territorio castellano, de la observancia del nuevo procedimiento administrativo y político que los municipios tenían que realizar para alcanzar la presupuestada modernización del estado ${ }^{21}$.

Los corregidores se vieron adornados de múltiples responsabilidades entre las que destaca el mantenimiento del orden público en los lugares de su jurisdicción, y

presupone que un señorío eclesiástico de corte tradicional estorbaba los intereses de control monárquico sobre las urbes e impedía la concesión de oficios a su albedrío. Se puede seguir más profundamente en: ESTEBAN RECIO, A.: Palencia a fines de la Edad Media. Una ciudad de señorío episcopal. Valladolid, 1989. Para la ciudad de Guadalajara se puede seguir la obra de Layna para comprender la influencia de la familia aristocrática de los Mendoza sobre los moradores de una población que desde siempre tuvo la constitución de realenga. LAYNA SERRANO, F.: Historia de Guadalajara y sus Mendoza. Madrid, 1942. IV Tomos.

18 Resultan especialmente interesantes las ideas de Maravall sobre las mentalidades que planean sobre el poder municipal y su evolución en la Baja Edad Media y la Edad Moderna. MARAVALL, J.A.: Estado moderno y mentalidad social (siglos XV al XVIII). Madrid, 1972. 2 vols.

19 GONZÁLEZ ALONSO, B.: op. cit., p. 35.

20 LUNENFELD, op. cit., p. 67.

21 Regina Polo en su indispensable obra sobre el régimen municipal en Castilla a fines del medievo hace una disección pormenorizada de los oficiales concejiles bajomedievales y nos recuerda que la actuación de los corregidores fue la clave para la pacificación de la convivencia ciudadana así como otras muchas cuestiones referentes a la aplicación de las normativas surgidas de las cortes de Toledo. POLO MARTÍN, R.: El régimen municipal de la corona de Castilla durante el reinado de los Reyes Católicos (Organización, funcionamiento y ámbito de actuación). Madrid, 1999, p 33 
ciertas cuestiones asociadas como la custodia de la cárcel y de los detenidos en ella, además de otras intervenciones entre las que se pueden destacar: la presidencia de las reuniones del cabildo donde se situaba en un lugar central, con lo que ello comportaba, o la potestad normativa dentro del concejo lo cual le permitía actuar sobre las ordenanzas municipales con habitual acuerdo del regimiento y siempre bajo control real. Desde dicho ordenamiento controlaba la hacienda concejil y mantenía el orden público, sin olvidar todo lo referente a otras funciones concernientes a la abigarrada actividad de los municipios que llevaba consigo, desde la gestión de los abastos hasta la dirección de las huestes concejiles en el caso de que hubiese necesidad de las mismas. La responsabilidad de su actuación se verificaba por medio de la exigencia que suponía el juicio de residencia al final del ejercicio del cargo.

Fue, consecuentemente, una figura omnipresente que no podía faltar en ninguna de las actuaciones municipales, porque en la estructura jurisdiccional ocupaba el puesto preeminente que le venía dado por la autoridad real. Sucedía a veces que la figura del corregidor podía estar ausente de la localidad por otros asuntos más apremiantes o simplemente porque no existía corregidor en la población. En ese caso, los encargados de administrar las causas y de ordenar ejecutar lo acordado eran los miembros del concejo representados en los regidores. De cualquier modo, a la hora de llevar a cabo lo decidido sobre las actuaciones judiciales por el propio corregidor o por el concejo en su ausencia, se ponían en marcha ciertos oficiales concejiles, como los alcaldes y alguaciles.

Todo lo anterior podría acercarnos a una realidad general, pero si nos referimos a singularidades, tal como la que se dio en la población de Guadalajara, que, pese a ser villa de relengo y debido a la permanencia de la familia Mendoza en la misma, negó a los reyes cualquier tipo de intervención política o social en la misma, al menos desde finales del siglo XIII, exceptuando algunos momentos de graves alteraciones en el gobierno local o revueltas sociales, nos encontraremos ante un interesante ejemplo de ausencia de oficiales reales ${ }^{22}$.

Sin duda alguna la propia naturaleza del cargo de corregidor resultaba opresiva para los concejos a los que iba destinada su actuación, por lo tanto sus nombramientos no fueron multitudinarios ni mucho menos de carácter permanente, sino que se limitaron a dirimir ciertas controversias y sus destinos duraban lo que persistía el problema en resolverse. A pesar de los reiterados intentos de Enrique III y de su sucesor Juan II, hasta los años de Enrique IV, no era un funcionario completamente extendido, de hecho habrá que esperar a las fecundas cortes de Toledo de 1480, ya en tiempos de los Reyes Católicos, para que se dicten una serie

22 Para conocer más profundamente la evolución de los corregidores en Guadalajara es necesario acercarse al artículo de Aurelio García López: «Prosopografía y Corregidores. El ejemplo de la ciudad de Guadalajara (siglos XVI-XIX)». En La Administración de Justicia en la Historia de España. Actas de las III Jornadas de Castilla-La Mancha sobre Investigación en Archivos. Guadalajara. Noviembre 1997. Junta de Comunidades de Castilla-La Mancha. ANABAD Castilla-La Mancha. 1999, pp. 193-218. 
de normas generales sobre dichos oficiales. En Guadalajara la figura del corregidor no apareció de modo permanente hasta mediados del siglo XVI. Pero fue doscientos años antes cuando el 23 de mayo de 1341 llegaron por primera vez unos alcaldes veedores llamados Diego Juan de Santo Tomé y Juan Martínez Jurado, que como enviados regios comparecieron en la villa de Guadalajara en un tumultuoso y complejo contexto político para «corregir los fechos de la tierra» por medio de unas ordenanzas de oficios ${ }^{23}$. Pocos años más tarde, en 1346, otros alcaldes de la reina, Tel Fernández de Toledo y Garci Triguero del Toro, nuevamente se presentaron en la villa para enmendar ciertas cuestiones que las anteriores ordenanzas no habían conseguido rectificar ${ }^{24}$.

Apenas comenzado el siglo XV, el rey Enrique III, durante el año 1401, aprovechó la ausencia del almirante Diego Hurtado de Mendoza, poder fáctico más importante de la población, para enviar a micer Ventura Venzón, el primer corregidor del que se tiene noticia en la villa. Se desconoce si su labor como corregidor fue la adecuada, pero desde luego no fue lo suficientemente duradera para conseguir que la figura de este oficial se consolidase, porque unos meses más tarde el propio rey devolvió al Almirante la posesión de los oficios ${ }^{25}$. Nuevamente los reyes aprovecharon una circunstancia excepcional, esta vez la muerte del citado Almirante, para enviar a Guadalajara un nuevo corregidor, lohán de Sant Andrés, que intentó corregir en 1417 algunos agravios que los alguaciles y otros oficiales concejiles cometían habitualmente por no haber claridad en la normativa local y por la ausencia sempiterna de los corregidores ${ }^{26}$. El historiador local Alonso Núñez de Castro que escribió en el siglo XVII, siguió para sus disertaciones los Anales de Guadalaxara, una obra, hoy perdida, de Francisco de Medina y Mendoza según la cual se aportan ciertos datos de presencia del corregidor Pedro de Guzmán en el año $1455^{27}$. Otros autores contribuyen con ciertas noticias sobre la presencia de corregidores a fines de siglo en el año $1494^{28}$.

La larga ausencia de estos oficiales en una ciudad de estatuto real se comprende por la fuerza que ejercía la familia Mendoza sobre la ciudad y su alfoz. De

${ }^{23}$ LOPEZ VILLALBA, J.M.: «Concejo abierto, regimiento y corregimiento en Guadalajara (13461546)» Espacio, Tiempo y Forma. Serie III, 5 (1992), p. 73.

24 LOPEZ VILLALBA; Idem., p. 67.

25 Opina Emilio Mitre que en Guadalajara se escenificó uno de los más claros fracasos de la política regia en la extensión de los corregidores. MITRE FERNÁNDEZ, E.: La extensión del régimen de corregidores en el reinado de Enrique III de Castilla. Valladolid, 1969.

${ }^{26}$ Dentro del preámbulo de las ordenanzas de la villa de Guadalajara de 1417 se puede leer: «... que por razón que en los tiempos pasados tanto que los oficiales de las alcaldías e juraderías e alguaziladgo de la dicha villa tovieron el dicho consejo e cavalleros e escuderos e omes buenos, segund que los antes tenían e tienen non aviendo corregidores en la villa, como después acá que avía nasçido e rrecresçido entre ellos muchas disinsiones e discordias, ansí por muchas obscuridades que avía en el fuero e hordenanças de la dicha villa...». LÓPEZ VILLALBA, op. cit., p. 75.

27 NUÑEZ DE CASTRO, A.: Historia eclesiástica y seglar de la muy noble y muy leal ciudad de Guadalaxara. Madrid, 1653.

${ }_{28}$ Tarsicio de Azcona en su obra: Isabel la Católica. Estudio crítico de su vida y reinado. Madrid, 1964, p. 343. Igualmente lo cita ULLOA, M.: La hacienda real de Castilla en tiempo del reinado de Felipe II. Roma , 1963, p. 37. 
tal suerte que incluso durante el otoño de 1528, en pleno ejercicio de poder de Carlos I, las desavenencias generadas entre algunos representantes de la ciudad y el tercer duque del Infantado, Diego Hurtado de Mendoza ${ }^{29}$, motivaron el nombramiento del licenciado Andrés Ramírez de Alarcón, como corregidor ${ }^{30}$. Una vez resueltas las discordias que dieron lugar a su llegada, Alarcón se negó a abandonar la ciudad, posiblemente ante el temor que el Duque volviese a las andadas. Este último reclamó del Emperador lo que siempre habían hecho sus antepasados en similares situaciones, la devolución de la potestad de los oficios locales, en este caso concreto el nombramiento de los justicias. Nuevamente se encendió la chispa en una mecha inagotable que siempre daba lugar a los mismos conflictos entre idénticos actores, los Mendoza y la ciudad, por el equilibrio de las fuerzas sociales. La singular fuerza política del Duque del Infantado consiguió del Consejo de Castilla unos mandamientos fechados respectivamente los días 11 y 12 de agosto de 1529, para que el corregidor Ramírez de Alarcón y su teniente el licenciado Alonso de Sensever, dejaran sus cargos y entregaran las varas de justicia a los nuevos oficiales nombrados por Diego Hurtado. De facto el último día que el teniente Sensever apareció en las reuniones del concejo arriacense corresponde al día siguiente, el 13 de agosto, por lo que se ha de suponer que el cambio se aplicó con celeridad $^{31}$.

Apenas unos años más tarde un nuevo pleito motivado por la misma situación enfrentó nuevamente a la ciudad, que deseaba arrebatar al Duque del Infantado la potestad de nombramiento de los oficios concejiles en posesión de la familia desde el año 1395 en que el rey se los entregó al Almirante Diego Hurtado, con los omnipotentes Mendoza ${ }^{32}$. De este modo el rey Carlos I, se puede entender que aburrido de esta situación, que se había transformado en una fuente perenne de antagonismo local, intentó una solución de carácter salomónico, el nombramiento regio del corregidor aunque con el agrado del Duque. De este modo tan atípico llegó a Guadalajara Antonio de Quesada, catedrático en Cánones de la Universidad de Alcalá de Henares, que sería el primero de los corregidores que habrían de instalarse en dicha ciudad sin interrupción. El delegado regio Quesada permaneció en el ejercicio del cargo, gracias a las prórrogas tan habituales en la época, hasta el 28 de junio de $1545^{33}$.

Como se ha visto la figura del Corregidor, extendida ya con dilatada antelación por otras muchas ciudades castellanas, se resistió a instalarse en Guadalajara, de-

\footnotetext{
${ }_{29}$ Una extensa referencia a los hechos en LAYNA SERRANO, F.: Historia de Guadalajara..., Tomo III, pp. 107-109.

${ }^{30}$ ARCHIVO MUNICIPAL DE GUADALAJARA. (AMGU). Libros de Actas de Sesiones. Tomo 15281531. Fol. 2 verso.

${ }^{31}$ Por su parte, el corregidor Ramírez de Alarcón había salido de la ciudad el día 28 de junio de ese año con la excusa de un viaje. AMGU. Libros de Actas de Sesiones. Tomo 1528-1531. Fol. 98 verso.

32 LAYNA SERRANO, op. cit. Tomo III, pp. 173-174.

33 GONZÁLEZ ALONSO, plantea que: «La anualidad va siendo insensiblemente suplantada por la bianualidad, aunque los nombramientos siguen despachándose con arreglo a las más estricta anualidad anterior». El corregidor castellano ..., p. 156.
} 
bido sobre todo, a la fuerza política de la familia Mendoza que no deseaban que nadie fiscalizase sus actuaciones en esta población. De hecho, hasta la propia llegada de los alcaldes de términos, oficiales reales encargados de solventar pleitos de términos territoriales, a la ciudad de Guadalajara para resolver las competencias entre dicha población y sus aldeas daba lugar a continuos desacuerdos entre los implicados debido al carácter autocrático de dicha familia. Son de resaltar los enfrentamientos que sobre estos propósitos se remontan al primer tercio del siglo XV, cuando por aquellos años en la tierra de Guadalajara se encontraban incluidas, entre otras, hasta doce villas que Juan II había entregado en señorío a Iñigo López de Mendoza. Estas villas y sus jurisdicciones provocaron una serie de hostilidades que obligaron al rey a enviar a un juez de términos que acabase con las colisiones surgidas en los procesos de deslindes ${ }^{34}$.

\section{Los alcaldes y jurados}

Para continuar este recorrido, obligadamente breve, por los oficios capitulares del concejo medieval resultará interesante detenerse en las figuras de los alcaldes, jurados, alguaciles y algunos de sus hombres, dejando la actuación de los escribanos para un acercamiento más específico en ocasión posterior.

Según la opinión de los especialistas, los jueces por antonomasia son los alcaldes $^{35}$. Ellos son los que aplican su trabajo para resolver las controversias municipales de todo tipo durante el dilatado periodo medieval. La obsesión regia por acortar las alas de la autonomía concejil logró, ya desde el reinado de Alfonso XI, que los jueces regios, encabezados por el corregidor debidamente instalado por ley desde el ordenamiento de Alcalá de 1348, fueran minando con lentitud pero sin descanso la actuación de la justicia municipal.

Así pues, largo tiempo hubo de pasar desde que los reyes castellanos del siglo XIII comenzaron los albores de su ofensiva contra los modos de justicia local aplicados en los concejos, propios de la escasa pero segura autonomía en que estos se movían, hasta la definitiva aplicación en tiempos de Alfonso XI, en que quedaron constituidas, de facto, dos tipos de aplicación de la justicia municipal y que estaba directamente relacionada con el tamaño de los mismos. Los lugares menores, con pocos habitantes o de escaso interés para la Corona, solían en muchas ocasiones pertenecer a la jurisdicción de otros municipios mayores, lo que les restaba la capacidad de su propio ejercicio judicial. En ocasiones se dirimían negocios que buscaban resolver pleitos en los que se barajaban algunas cuantías destaca-

34 Para ampliar la actuación de los jueces de términos en Guadalajara y su término. GATTI DÍAZ, M. O.: «Los jueces de términos en Guadalajara». En La Administración de Justicia en la Historia de España. Actas de las III Jornadas de Castilla-La Mancha sobre Investigación en Archivos. Guadalajara. Noviembre 1997. Junta de Comunidades de Castilla-La Mancha. ANABAD Castilla-La Mancha. 1999, pp. 219-234.

${ }_{35}$ Voz alcalde en Enciclopedia de Historia de España, dirigida por Miguel Artola, vol. V. (Barcelona, 1988-1993), p. 25. 
bles que obligaban a que fuesen resueltos por los justicias de las villas o ciudades a los que pertenecían y no por los del lugar donde residían. Los hechos de este contexto sobrellevaban una serie de penalidades a los habitantes de estos lugares que de este modo quedaban desamparados. En primer lugar porque la justicia era impartida por personas ajenas a su medio vital, lo cual acarreaba muchos inconvenientes entre los que no era el menor los desplazamientos a los que se veían abocados hasta la cabecera jurisdiccional. De cualquier forma, el intervencionismo regio actuó, respecto a estas razones, con tanta contundencia como complacencia hacia sí mismo, ya que por un lado permitió una cierta patrimonialización de los oficios jurisdiccionales en las pequeñas aldeas, aunque siempre desde la aparente permisividad se escondía un control indirecto de lo sucedido.

Por otro lado, este control se acentuaba en las ciudades y villas de su plena competencia generando el segundo tipo de justicia local que se aludió con anterioridad, la representada por los oficiales reales. Los corregidores como factotum máximo de la autoridad regia, con más frecuencia de la deseable, nombraban a los poseedores de las alcaldías y alguacilazgos, con lo que se extendía la tela de araña clientelar que llevaba incorporado el control de la urbe por la Corona. No era infrecuente pues que con los nombramientos indebidos se acentuase el descontento generalizado entre muchos de los habitantes de las mismas, que, por un lado, eran sometidos a una carga económica elevada para el pago de los salarios de tan excedida nómina de oficiales, y además se veían afectados por los abusos cometidos con frecuencia en la puesta en práctica de una justicia local que generalmente actuaba en beneficio de los grupos de poder.

Fue en dicho espacio local donde el nuevo sistema de control que la monarquía quiso implantar a partir del Ordenamiento de Alcalá tuvo una mayor oposición porque veían en esta intervención regia una pérdida creciente del autogobierno que habían practicado durante un prolongado periodo. Sin olvidar en ningún caso que la facultad de legislar corresponde en todo caso al monarca y que desde el comienzo evolutivo de su potestad legislativa pudo decretar las normas con carácter general, sobre todo a partir del siglo XI, aunque siempre con la anuencia de las curias y después de las Cortes.

Los jurados representan un oficio municipal algo disperso en sus objetivos y que a lo largo del periodo medieval aparece en las fuentes documentales bajo diferentes significados. Entre otros orientaciones, a partir del siglo XIII se distinguen como representantes de los intereses concejiles y como controladores de otros ofi$\operatorname{cios}^{36}$, aunque su casuística laboral era tan variada que aparecen incluso actuan-

${ }^{36}$ Sobre la figura de los jurados interesa visitar, entre otras, la obra del profesor José María Monsalvo que realiza un análisis sistemático de los jurados que sigue y amplía Regina Polo. MONSALVO ANTÓN, J. M.a: «La participación política de los pecheros en los municipios castellanos de la Baja Edad Media. Aspectos organizativos». En Studia Histórica. Historia Medieval. VII (1989), pp. 37-93. POLO MARTíN, R.: op. cit., pp. 235-318. Asimismo es conveniente la lectura de: CERDÁ RUIZ- FUNES, J.: «Hombres buenos, jurados y regidores en los municipios castellanos de la Baja edad Media». En Actas del I Symposium de Historia de la Administración. Alcalá de Henares, (1970), pp. 163-206. 
do en algunos pleitos ${ }^{37}$. Si en un análisis originario se observa como en los siglos centrales del medievo los jurados obedecen a diferentes comedidos, bien como autoridades de justicia, bien como gestores con un claro desempeño administrativo ${ }^{38}$, ya en la Baja Edad Media se consolidarán como representantes de las collaciones, antes de dar un giro sorprendente fundamentando su trabajo como oficial real. Aunque en un principio no se señalaron con claridad el número de representantes parroquiales en el gobierno de las localidades, ya en el siglo XIV se manifestaba una tendencia generalizada a elegir dos jurados por cada una de las collaciones o parroquias, aunque con excepciones variadas que contradicen la norma ${ }^{39}$. La selección de los jurados se realizaba bajo el amparo de ciertos privilegios que se pueden observar a partir de Alfonso X en el marco de la intervención regia en los gobiernos concejiles y que aumentará a partir de Alfonso XI, hasta alcanzar las elevadas cotas del siglo XV, de modo que en tiempos de los Reyes Católicos, apenas se pueden señalar algunas localidades donde los jurados se continúen eligiendo por los vecinos ${ }^{40}$, aunque la intervención real no mantuvo el mismo nivel de intensidad en todas las ciudades ${ }^{41}$.

Las funciones de los jurados son en extremo variadas, destacando en primer lugar la representación vecinal y las actuaciones de control y ayuda a otros oficios concejiles, como los regidores. En el supuesto que se presenta interesa más su función como oficiales de justicia en lo que algunos autores han dado en llamar «jurados de tipo antiguo», que desempeñan ciertas actividades de vigilancia en hechos económicos y aparecen junto con los alcaldes llevando a cabo tareas gubernamentales o de funcionarios judiciales ${ }^{42}$. En esta faceta de comisionados ejecutantes de la norma aparecen en las ciudades y las villas desempeñando un papel

37 Para la villa de Guadalajara aparecen en las circunstancias más diversas. LÓPEZ VILLALBA, J.M.: Concejo abierto..., pp. 65-84.

38 Es de obligada lectura el planteamiento que realiza MONSALVO ANTÓN, J.M.: «La participación política de los pecheros en los municipios castellanos de la Baja Edad Media. Aspectos organizativos». Studia Histórica. Historia Medieval. VII (1989), pp. 37-93.

39 Por no resultar exhaustivo sólo se pondrán los ejemplos de Sevilla y Guadalajara. La primera de las dos poblaciones contaba a mediados del siglo XIII con tres jurados por parroquia y en la villa de Guadalajara a comienzos del XV únicamente era representada por un jurado por cada una de las collaciones. Para Sevilla, LADERO QUESADA, M.A.: Historia de Sevilla: La ciudad medieval (1248-1492). Sevilla, 1976. Para el ejemplo de Guadalajara. LAYNA SERRANO, F.: Historia de Guadalajara... Madrid, 1942. 2 vols.

40 Entre la escasa documentación al respecto destaca la aportada por VILLEGAS DIAZ, R.: Ciudad Real en la Edad Media. La ciudad y sus hombres (1255-1500). Ciudad Real, 1981, pp. 125-126.

41 Regina Polo hace una disección pormenorizada de las elecciones del oficio de jurado, dividiendo las designaciones de los reyes en: 1) Simple confirmación regia de la elección realizada por otras instancias, que pueden ser las llevadas a cabo por los vecinos de las collaciones o de particulares a través del mecanismo de las renuncias. 2) Designación libre o plena disposición de los reyes, que a su vez subdivide en acrecentamientos, cartas expectativas, vacantes que se producen por diversas causas. POLO MARTÍN, R.: El régimen municipal..., pp. 258-265.

42 Esta acepción que ha propuesto Regina Polo en su obra repetidamente nombrada, responde a uno de los ejemplos más característicos que se presenta en las ciudades del norte de la Corona en la que los oficiales están señalados por su actuación ejecutora. Entre otras investigaciones se puede señalar: SESÉ SORIA, L.: Derecho municipal guipuzcoano (categorías normativas y comportamientos sociales). Bilbao, 1992. 
de agentes reglamentarios que prenden a los malhechores, embargan los bienes que hubieren para ponerlos a subasta, conducen a los delincuentes a la cárcel y cobran las penas que se les impusieren ${ }^{43}$. En una palabra, siguieron manteniendo aquellas funciones que realizaban en las sociedades urbanas de los siglos plenomedievales y que les reportaba una cierta dignidad municipal ${ }^{44}$. Por otro lado, en una observación meramente geográfica se comprueba, siguiendo las publicaciones sobre esta cuestión, que al norte de la línea divisoria del río Tajo sus referencias documentales se hacen infrecuentes o son de escasa representación dentro de la organización asociativa del común. Respecto a los jurados de la ciudad de Guadalajara, objeto principal, junto a los demás oficiales judiciales locales, de este estudio, aparecen ya a comienzos del siglo XIV, en las ordenanzas de 1405, representado a las collaciones, uno por cada una de las parroquias de la villa y gozando de unas claras atribuciones jurisdiccionales que mantendrán en las siguientes ordenanzas fechadas el año $1417^{45}$. Su actuación en los pleitos no era generalizada sino que aparecen en actuaciones concretas en las que existen conflictos entre los moradores cristianos y los judíos o moros, pero advirtiendo que únicamente en el caso en que los culpados sean los judíos o los moros sería requerida su intervención. Además dentro de la función jurisdiccional que desarrollan también entran a dirimir en la cuestión económica del concejo por medio de la resolución de las apelaciones de los almotacenes o llegan a emitir dictamen sobre las ejecuciones de las rentas de los propios de la dicha villa. En cualquier caso en Guadalajara, respecto a la temporalidad del cargo de jurados, al igual que en otras ciudades castellanas, dichos oficiales evolucionaron desde la anualidad y la elección vecinal hacia su transformación en oficios designados por el rey con una marcada tendencia a la duración vitalicia, y gozando de la capacidad de la renuncia acabaron siendo patrimonializados. De este modo desde mediados del siglo XV adolecían de todos los males de otros oficios locales, ya que no sólo dejaron de representar aquellos objetivos para los que nacieron sino que entregados por los reyes como merced a los señores de las ciudades, como era el caso de los Mendoza, se transformaron en una arma arrojadiza contra el común desde las oligarquías dominantes.

Antes de continuar, es conveniente señalar el origen de la fuente, las Ordenanzas de los derechos de los oficios concejiles de Guadalajara, redactadas en 1463, que ha servido como soporte vertebrador de este trabajo. Dicha normativa ya era conocido por el autor que en su día consideró la oportunidad de su publica-

43 POLO MARTÍN, El régimen municipal..., p. 236.

44 Se puede ver un recorrido por las actividades de los jurados altomedievales en: CARLÉ, M. del C.: Del concejo castellano leonés. Buenos Aires. 1968, p.118 119.

45 Sobre el carácter propio de las juraderías de Guadalajara en la Baja Edad Media, hay una cierta controversia representada por dos autores. El historiador de los Mendoza alcarreños, Layna Serrano, afirma la existencia de una clara naturaleza jurisdiccional que continuará a lo largo de las siguientes normativas locales, mientras que la medievalista Caroline Mignot, mantiene la existencia de una dualidad en la función de los jurados, que se debaten entre la actuación judicial y una cierta condición de representantes vecinales. LAYNA SERRANO, F.: Historia de Guadalajara y sus Mendoza en los siglos XV y XVI. Madrid, 1942. 2 vols. MIGNOT, C.: Le «municipio» de Guadalajara au XVeme siecle, systeme administratif et economique (1341-1567), Anuario de Estudios Medievales, 17 (1989), pp. 581-609. 
ción ${ }^{46}$. De este modo el hallazgo y divulgación de cualquier ordenanza municipal medieval, dada la relativa escasez de fuentes normativas para este período, es una labor necesaria. Por ello, en su día se acometió el trabajo de transcripción, además de un breve estudio introductorio general y codicológico en particular, sobre el soporte de dichas ordenanzas que resultó ser un manuscrito integrado por 12 cuadernillos de papel, irregulares en su extensión.

La citada normativa fue realizada por mandato de los regidores de la ciudad a Gonzalo Ruiz de Villena, regidor, y a Fernando Jiménez de Toledo, contador, ante la falta de claridad dispositiva referente al cobro de las tasas por parte de los oficiales, con los consiguientes abusos por parte de éstos. Aunque incompletas, tal vez por un lapsus o por no poseerlas en su integridad el escribano que las trasladó, han aportado una fuente de estudio de indudable importancia, no sólo para el conocimiento de la Guadalajara medieval, sino para un análisis más general de los oficios del concejo en la baja edad media, logrando con los nuevos datos un mayor entendimiento de las instituciones de gobierno local. No se debe omitir que si hay algo que permita aclarar las profusas dudas sobre el funcionamiento de las entidades urbanas medievales es la articulación de su vida administrativa.

Los alcaldes y los jurados, como el resto de los oficiales locales, recibían una serie de cotos por las actuaciones que realizaban. Respecto a los primeros, y sin entrar en una profundización excesiva, se puede afirmar que su intervención resultó de vital importancia en los múltiples y complejos sistemas de justicia medieval municipal por la cual obtenía una serie de derechos económicos, que en el caso estudiado no representaban cantidades elevadas si se cuantifican individualizadamente, pero habida cuenta del número de procesos y la complejidad de las actuaciones en cada uno de ellos, entre dentro de lo probable, que la cifra a percibir fuera respetable.

Los alcaldes ordinarios de Guadalajara eran cuatro y juraban su cargo por un año en la iglesia de San Gil. Estos alcaldes habían tenido en la ciudad una gran importancia como «curia alcaldum", hasta la llegada de los regidores en los comienzos del siglo XV. El número de los jurados también era de cuatro, uno por cada collación de la villa. Debían cumplir una serie de relevantes condiciones, para recibir la carta del rey con el nombramiento perpetuo ${ }^{47}$.

46 Dichas ordenanzas fueron encontradas casualmente en la Biblioteca del Real Monasterio de El Escorial. Códice X II 19, páginas 142r a 162v; y pueden verse publicadas en LÓPEZ VILLALBA, J. M.: «Estudio y transcripción de las ordenanzas de derechos de los oficios del concejo de Guadalajara de 1463». En Espacio y Fueros en Castilla-La Mancha (Siglos XI-XV). Una perspectiva metodológica. (1995), pp. 323-350.

47 AMGU. 1H3.8a. «...e que estos jurados que no sean más de quatro e que sean tales que convengan e contiosos e de buenas conçiençias, porque ansí cunple a serviçio de Dios e del dicho señor rrey e poblamiento de la dicha villa e su tierra....". Infelizmente la documentación medieval del Archivo Municipal de Guadalajara (AMGU), sin ser escasa, se presenta tipológicamente dispersa, sin series completas, por lo que la llamada tiranía de las fuentes se manifiesta en toda su crudeza. A modo de ejemplo y por lo que respecta a las actas capitulares, hay una verdadera escasez, ya que las primeras que poseemos son las del año 1454, siguiendo para dicho siglo, las de 1475, 1485, 1496 y 1500, todas ellas in- 
Estas ordenanzas desarrollaban los derechos que han de llevar ambos cargos con un amplio recorrido por sus competencias, que habían aumentado claramente respecto a las anteriores ordenanzas de oficios dictadas en el año 1417. Con la nueva normativa pueden controlar situaciones tan diversas como la autorización de una letra de escribano, llevar derechos sobre los testamentos hechos sin escribano, hacer inventarios de bienes de los fallecidos, podían asentar tutores o curadores, mandar hacer publicaciones de testamentos, aunque el testamento estuviese hecho sin escribano público. Además se presentaban ante los dichos alcaldes ordinarios, procesos apelativos de la villa de Peñalver y de otros lugares, que aunque alejados de la ciudad tenían por costumbre que todos los agravios los resolviesen dichos alcaldes de Guadalajara. Entre otras muchas ocupaciones de carácter común, alcaldes y jurados, aparecen juntos resolviendo los pleitos en el concejo público los lunes, miércoles y viernes, a la hora de la tercia y de las vísperas. Del mismo modo, podían librar dichos pleitos los martes, jueves y sábados, siempre que fuese en sus casas. Según se ha podido observar alcaldes y jurados se presentan en compañía solventando cualquier asunto en común y por ello alcanzaban los mismos peculios por el desempeño de sus diligencias. Por las actuaciones de carácter menor, como los mandamientos facultados de palabra para hacer una ejecución, ambos llegaban a cobrar un maravedí. Si lo ordenaban por escrito la cantidad se elevaba a dos maravedís.

La actuación judicial o administrativa de los moradores de las poblaciones ante la previsión de la muerte no era labor exclusiva de los escribanos públicos, porque alcaldes y jurados se veían capacitados, por la normativa estudiada, a dar validez a los contenidos testamentarios cuando estos se testificaban en aldeas 0 lugares que no conocían de la existencia de notarios y eran consumados por algún eclesiástico u otra persona experta en el arte de la escritura, pero que en ningún caso poseían la autoridad para signarlo y darle eficacia como documento de prueba aunque estuviese concluido ante testigos. Sus funciones no acababan en la legitimación de los citados testamentos, puesto que hacían un seguimiento que finalizaba con la publicación del mismo. Por tales intervenciones cobraban en dos veces, una por la comprobación de los datos contenidos y su publicación, la cuantía de seis maravedís; y por la averiguación de lo acontecido, justo el doble, doce maravedís. Si son llamados con posterioridad al fallecimiento del interesado y se les requiere para hacer el inventario de las posesiones del finado, la cantidad a cobrar es la misma. La tradición testamentaria ha sido una constante en las sociedades occidentales, pero no sólo en la hora final desean las personas ordenar sus heredades, puesto que en muchas ocasiones se torna necesario el discernimiento explícito de todas las propiedades por medio de un inventario. El conocimiento en profundidad de los bienes poseídos podía, en ciertas coyunturas, poner freno a

completas. Todas ellas fueron transcritas y publicadas en el año 1997. LÓPEZ VILLALBA, J.M. Las Actas del concejo Medieval de Guadalajara. Madrid. UNED. 1997. Recientemente en el Archivo de Nobleza en Toledo se ha reubicado un libro del concejo de Guadalajara que contiene actividades del mismo correspondientes a la década de 1491-1500. 
muchas ocupaciones indebidas $u$ otros percances, que resultaban finalmente ser motivo de querellas. La figura del alcalde se tornaba árbitro de tal situación, porque dirigía el apeo solicitado eligiendo y requiriendo a ciertos hombres que apeasen el conjunto de las tales heredades y más tarde recibía de ellos el juramento adecuado, a continuación lo firmaba dándole la legitimidad pertinente, por lo que recibía la cantidad de veinticuatro maravedís. En algunas ocasiones la realización del apeo se presentaba más complicada de lo deseado por lo que se requería la presencia del alcalde junto con los apeadores. En este caso, cambiaba el tipo de percepción pecuniaria, puesto que al compromiso de pago por la actuación administrativa se unían los viáticos por la permanencia en el terreno a inventariar ${ }^{48}$.

Resulta curioso observar que antes de la instauración de estas ordenanzas sobre la percepción de derechos de los oficiales, los alcaldes, ni los jurados ni otros jueces percibieran salario alguno por el interrogatorio de los testigos presentados en algunos negocios. Los citados declarantes eran derivados hacia los escribanos que acometían los cuestionarios sin las garantías suficientes, con los consecuentes perjuicios ${ }^{49}$. Para acabar con esta problemática se les reconoció el derecho a cobrar por las indagaciones en función del número de testigos que se presentaran a declarar. El pago del trabajo llevado a cabo por el investigador se financiaba por los implicados en la diligencia, siendo el contribuyente aquel que recibiese el favor de los declarantes en sus manifestaciones. Los pagos se gestionaban de la siguiente manera: de un testigo hasta seis el derecho era de un maravedí por cada manifestante, mientras que desde seis hasta veinte testigos se cobraba dos maravedís por declarante. Cuando el asunto a tratar en el proceso era importante o demasiado complejo y se superaba la cantidad de veinte testigos los cotos a cobrar quedaban al arbitrio del tasador de la ciudad. También solía acontecer en algunos casos que se cobrasen excesivos devengos en la tramitación de ciertos asuntos referentes a los cobros de las rentas de los arrendadores de las alcabalas y propios de la ciudad ${ }^{50}$.

El ordenamiento de Alfonso X, aprobado en las Cortes de Zamora de 1274, recoge la figura de los alcaldes de alzadas, de los que nos dice Valdeavellano que «eran jueces que entienden de las apelaciones de las sentencias de los demás jue-

48 LÓPEZ VILLALBA, J. M.: «Estudio y transcripción..., : «E sy cosa fuere que el tal alcalde oviere de yr a fazer el tal ynventario con los apeadores, demás de sus derechos, le fagan la costa e le den veynte maravedís cada día de los días que estoviere en fazer el dicho ynventario, e esto que sea avido por buen ynventario» p. 336.

49 LÓPEZ VILLALBA, J. M.: idem ..., :«rremiten la rreçebçión... los testigos a los escrivanos ante quien pasan los pleitos, non seyendo razón. E por esta causa non son interrogados e preguntados los testigos como deven» p. 337.

50 LÓPEZ VILLALBA, J. M.: ibidem..., «Por ende, de aqui adelante, se lleven los derechos en esta guisa: De las abenençias de las dichas rrentas, que paresçieren por escrivano o por testigos, que sean sesenta maravedís arriba, dos maravedís de mandamiento e más entrega. E de las debdas e abeneçias, de sesenta maravedís ayuso fasta veynte, la entrega e non más. E de las abenençias que non paresçieren por ante escribano, nin testigos non fagan esecuçión fasta ser averiguado la abenençia e si la fizieren non lleven derechos algunos fasta ser averiguado. E sy esta tal copia se diere a esecutar al alguazil, lleve el alguazil las entregas e al allcalde sus mandamientos», p. 338. 
ces de las comarcas o territorios del reino „51. Su presencia en estas normas de 1463 , como era de prever, es muy escasa. La desarrollan como figura preeminente en la presentación de procesos civiles en grado de apelación, por lo que cobraban doce maravedís. Asimismo su relevancia les hacía llevar el doble de los derechos que tenían que cobrar los alcaldes ordinarios ante cualquier intervención. Es de presumir que actuarían cuando los pleiteantes de cualquier tipo de proceso no se consideraban suficientemente complacidos y apelaban en segunda instancia a los alcaldes de alzadas, que en este caso al tratarse de una ciudad de realengo, serían los que el rey designase.

\section{Los alguaciles y sus ayudantes}

Merecen los alguaciles y sus ayudantes párrafo aparte en esta aproximación a los oficios judiciales locales, porque dichos oficiales soportaban las numerosas y variadas actividades en aras del cumplimiento del proceso que se seguía a los acusados con las correspondientes carcelerías anejas; o las entregas, que tanto en la ciudad como en las aldeas debían realizar; sin olvidar que por encontrarse bajo el mando directo de alcaldes y regidores estaban obligados a ejecutar todas aquellas cosas que estos les ordenasen.

Lógicamente ejercen sus competencias sobre los vecinos y moradores de la villa y tierra con todas las aldeas sobre las que desplegaban su autoridad. Cuando se trataba de encarcelar a cualquiera que hubiese cometido un delito, los alguaciles debían estar supeditados a la autoridad reglamentaria del concejo, los alcaldes y en su caso los jurados. De este modo, una de sus actividades primordiales, entre otras muchas, se basaba en la resolución de los problemas que hubiesen generado deudas con el concejo. En muchas ocasiones se veían obligados al encarcelamiento del deudor, por lo que recibían la cantidad de doce maravedís. Así cuando se trataba de herrar a los confinados o de quitarles los herrajes en el supuesto de que hubiese que liberarlos, los alguaciles cobraban la cantidad de cuatro maravedís, siendo el doble cuando se trataba de los grupos sociales señalados con anterioridad. En el supuesto de que el entrampado fuese hidalgo, eclesiástico o perteneciente a las minorías judía o musulmana, se llevaba doblado el precio del encarcelamiento.

Los desembolsos por estas intervenciones quedaban a cargo del concejo que procuraba eludir el pago cuando excedía algunas cantidades consideradas inconvenientes. La casuística de los encarcelamientos era múltiple, como variadas fueron las causas que llevaban a los acusados a la cárcel, por ello las retribuciones recibidas eran muy diversas. En un acercamiento somero a las mismas se puede destacar las motivadas por débitos, en el supuesto de que fueran muchos los

51 GARCIA DE VALDEAVELLANO, L.: Curso de Historia de las Instituciones Españolas. 5. ${ }^{a}$ ed. Madrid: Revista de Occidente, 1977. pp. 562-565. 
deudores en una misma causa y por tanto se generasen gastos elevados para la detención, el transporte de los presos, el herraje de los mismos y la posterior carcelería, el monto de los citados desembolsos era pagado por los encausados y se repartía entre todos ellos. Nuevamente se repite esta situación cuando los presos lo son por una causa criminal. En este supuesto se necesitaba aumentar la guarda ante la mayor posibilidad de una fuga y eran los propios detenidos los que costeaban dichos custodios, siempre ha de entenderse, que la solvencia económica lo permitiese. Por otro lado, cuando esta labor era ordenada por alguien que, aunque perteneciese al concejo, no tenía la jurisdicción del juzgado los que realizasen estas empresas no alcanzaban derecho a percibir ningún salario. De este modo, al no percibir cantidad alguna por actuaciones poco claras o sin regulación, los oficiales menores invariablemente procuraban ocuparse de lo que les mandaban sus superiores directos con lo cual se evitaban ciertos engaños institucionales.

Los oficiales no siempre acertaban en la detención de los presuntos culpables, podía acontecer que se equivocasen en la identificación de los mismos y en ese momento se les debía soltar antes de entrar a la cárcel. Los alguaciles, a pesar del error cobraban los derechos correspondientes a la detención y el traslado a la prisión que consistía en los cuatro maravedís sobredichos. Pero del mismo modo se prevé la posibilidad de que los oficiales fuesen a prender a ciertos perseguidos y no los hallasen, o bien que habiéndolos hecho prisioneros y realizado el camino hasta la audiencia llegasen mandamientos de que había que soltarlos, en cualquiera de los dos supuesto percibían igualmente el traslado ${ }^{52}$. En las ocasiones en que no se encontraba al imputado los alguaciles y su teniente habían de dar fe de lo sucedido ante el alcalde. En este caso la fe, documento concejil de comprobada importancia como documento de prueba, servía para que el juicio se pudiese llevar a cabo en rebeldía y los oficiales cobraban cuatro maravedís por su realización, aunque desconocemos lo que cobraría el escribano por pasarla a limpio.

La actuación del alguacil, al igual que la de los demás oficiales, no se circunscribía a la ciudad sino que se ocupaban al mismo tiempo de toda la tierra de la misma con sus aldeas. En estas ordenanzas de 1463, se puntualizan claramente los derechos que habían de llevar por los caminos que se realizaren para hacer las entregas o algunas otras cuestiones que afectaran al gobierno de la ciudad ${ }^{53}$. La regulación es la clara respuesta a unas presuntas estafas que habrían ocurrido, ya que si se observa esta disposición, en la teoría queda como regulación dineraria irrefutable, pero que se presenta proclive al engaño y al fraude. Es sorprendente

52 LOPEZ VILLALBA, «Estudio y transcripción de las ordenanzas ..., «lleven el derecho que avían de llevar por lo llevar e non otros derechos algunos, pues trabajó en lo yr a buscar e non lo falló» p. 341

${ }^{53}$ LÓPEZ VILLALBA, Idem..., «De Yriepal a Taracena e Marchamalo, quatro maravedís, e Valdenoches e Tórtola e La Casa e Fontanar e Valbueno e Alhovera, ocho maravedís. De Chilueches e Çelada e Albolleque e Benalaque e Cabanillas e Sant Martín e El Cañal e Çayde, seys maravedís. De Aldeanueva e Çentenera e Lupiana e Orche e Valverde e Yeves e Valdarachas e Monedero e Usanos e Fresno de Málaga e Açuqueca e Villanueva e Quer e Valdeaveruelo, diez maravedís. De Bujes, onze maravedís. De Malaguilla e Villaviçiosa, treze maravedís. De Renera e Valdeavellano, catorze maravedís. De Irueste e Yélamos, dieziseys maravedís... » p. 341. 
que si en un principio estaba pensada para que los jornales a obtener por el traslado de los oficiales se prorratearan entre todos los asuntos a realizar durante la empresa, sucedía demasiadas veces que no se repartía entre todos los visitados, sino que a cada uno de ellos se le cobraba el camino entero con los claros inconvenientes derivados de tan fraudulenta operación. Los alcaldes no debían confiar demasiado en los hombres del alguacil porque en ciertas ocasiones preferían enviar a algún andador o a sus propios ayudantes para resolver dichos quehaceres, aunque en este caso los sobredichos sólo podrían cobrar la mitad de las pagas que debían llevar los alguaciles.

En el hipotético caso de que las entregas se hiciesen en las comunidades o aljamas de las minorías religiosas, el dinero a percibir por la entrega era el doble de cuando se realizaba con cristianos, aunque por el camino se percibía la misma cantidad. Nuevamente se observa la preocupación de los legisladores porque los oficiales no se excediesen en las retribuciones más allá de lo que por norma les correspondía. De modo que cuando había muchos deudores en un único asunto los alguaciles debían repartir la entrega entre todos los culpables y no cobrar el derecho a cada uno como debían estar malacostumbrados hasta la promulgación de estas ordenanzas.

Por último, requieren nuestra atención, tres asuntos curiosos en los que intervenían los alguaciles. El comportamiento de las minorías religiosas ante las fiestas cristianas, la participación en los juegos de azar y finalmente, la jactancia y el uso de las armas en las calles y locales de la ciudad. Así pues se ha de comenzar por el control urbano que los grupos dominantes imponían sobre las minorías religiosas en un periodo pre-inquisitorial que se caracterizaba por una serie de actuaciones que buscaban ante todo la verificación de las actividades religiosas propias de dichas minorías o de aquellas otras que pudiesen atentar contra los preceptos de la religión oficial. Entre las segundas actuaciones, tal vez de mayor importancia por la trascendencia social que comportaban, quedaba regulado que los días considerados sagrados por los cristianos debían ser respetados en todo caso, puesto que eran consustanciales con la manifestación de la fe. De este modo los días de precepto obligatorio como domingos o feriados religiosos de los cristianos, los judíos y musulmanes no solían respetar uno de los mandatos más relevantes acudiendo a la celebración de la misa, aunque no eran perseguidos por ello. Pero por su parte, no debían romper la veda de las actividades manuales prohibidas en dichos días, sobre todo acometiendo labores que conllevasen ruido u ostentación de las mismas. Difícil encomienda la de trabajar en silencio, o con la mínima perturbación sonora, ante lo cual lo verdaderamente complicado para los infractores sería salir indemne del intento, porque los oficiales locales de justicia vigilaban que no se llevase a cabo ninguna actividad de este tenor con gran diligencia. Si no se lograba eludir la multa, su cuantía era de sesenta maravedís cada vez que fueren hallados en esta contravención de la norma. De las prendas que les tomasen los alguaciles se podían quedar con un tercio dando las dos partes restantes a los regidores locales. 
Resalta, en estas normas, la importancia concedida a la inmediatez que se impone en todo el proceso, con una rápida detención de los infractores así como de la inmediata imposición de la pena. Por esta actuación recibían la mayor tasa por el cobro de la sanción, al igual que por la urgente puesta en disposición de los regidores, que en este momento estuviesen en la ciudad, de la parte correspondiente de todo lo prendado. Para que la acción judicial se pudiese ejecutar sin demora los alguaciles podían actuar contra dichos quebrantadores, aun sin tener orden para ello. Si no lo hacía de este modo los alguaciles podían ser castigados con una pena, que se antoja excesiva, de seiscientos maravedís por cada vez que no cumpliese con su obligación a este respecto ${ }^{54}$.

La segunda de las actuaciones que se ha querido destacar por su peculiaridad es la referente a los juegos de azar que a finales de la Edad Madia se reducían, en la mayor parte de las localidades, a los dados y las cartas. Los juegos de azar fueron perseguidos con gran encono por los monarcas castellanos que vieron en ellos un gran perjuicio para la Corona así como para la fe católica. Por lo legislado parece que en la ciudad de Guadalajara los juegos de dados eran de generosa aceptación por los pobladores que se entregaban a ellos con desbordada ilusión. Contra esta costumbre, la normativa local, basada en las disposiciones generales de la Corona, los prohibía con fuerza, no permitiendo que se jugase ni en público ni encubiertamente, aún siendo esto último la práctica más habitual. En el supuesto de que fuese hallado un grupo de jugadores se les cobraba la cantidad de veinte maravedís a cada uno de los integrantes de la timba, además se multaba con sesenta maravedís al garito que servía como casa de juego, y por último se tomaban todos los dineros que estaban en ese momento en las mesas de esparcimiento. Dado lo seductor del juego y la generalización del mismo, es de imaginar la cantidad de dinero que esto movería, de tal suerte que se volvería interesante para los implicados en este negocio convencer a los oficiales concejiles para lograr su connivencia en estas prácticas por medio de su permisividad e incluso porque daban licencias para el juego e incluso llegando a conseguir lugares donde se pudiesen esparcir sin contratiempos. En compensación recibían parte del tablaje, es decir del porcentaje que recaudaban las casas de juego de todo el dinero que se manejaba en ellas. Entendemos que dada la seriedad de la disposición ${ }^{55}$, el otorgamiento de licencias quedaba fuera de toda regla municipal, de las familias nobiliarias de la ciudad, e incluso iba en contra de la normativa de la Corona, pero resultaría muy provechoso para aquellos alguaciles que se atreviesen a contravenir lo dispuesto otorgando dichas licencias fraudulentas. Para acabar con toda esta actividad claramente perjudicial a los intereses de tantos sectores se la persiguió con

${ }^{54}$ La mayor parte de las sanciones elevadas se destinaban a la reparación de los muros de la ciudad dada la mala calidad de adobe, material de clara herencia musulmana, que conformaba la estructura y que garantizaba una perenne debilidad de dichas defensas; así como al puente que salvaba el rio Henares en la zona norte de la ciudad. Pueden verse ejemplos evidentes en LOPEZ VILLALBA, J.M.: Las actas de sesiones ..., Madrid. UNED. 1997.

55 LÓPEZ VILLALBA, «Estudio y transcripción de las ordenanzas ..., «lo qual es, en deserviçio de Dios e del dicho señor Rey...», p. 342. 
obcecación e inclusive con irritación por el concejo, que imponía unas penas de dos mil maravedís contra el alguacil que diese el consentimiento. Si llegaba a reincidir la pena se doblaba y, por la tercera vez, además se le quitaba el oficio y se le tachaba de perjuro con las penas anexas, porque había quebrantado aquellas ordenanzas que juró defender.

Finalmente, aunque no con una importancia menor se debe mencionar la intervención de los alguaciles en los asuntos de la tenencia de armas y la ostentación de las mismas en las calles de la ciudad. Evidentemente, la posesión y uso de las armas creaba en la actividad cotidiana de las urbes una serie de problemas de convivencia que en ocasiones acababan con victimas debido a los graves disturbios que se originaban. Por este motivo, los alcaldes y alguaciles de Guadalajara junto con sus tenientes tenían órdenes de vedar la ostentación y el uso de las armas a todos aquellos que las llevasen a la vista por las calles de la ciudad, no estando permitido a los hombres a su servicio que ejecutasen este impedimento. Dentro de esta instrucción se había generado una excepción referida a los mercaderes y abastecedores de la urbe que llegaban con provisiones y otros encargos, y que en aras al carácter de su actividad no pasaban más de un día en la ciudad, no teniendo, de este modo, un lugar donde hospedarse y, por lo tanto, donde poderlas dejar ${ }^{56}$.

Las funciones de los alguaciles como oficiales ejecutivos a las órdenes del juez. eran las propias del mantenimiento del orden y del cumplimiento de la justicia, siendo ayudados por otros oficiales menores que nombraban ellos mismos y de los cuales debían responder ante la autoridad superior, como ya había quedado claramente especificado en las ordenanzas de $1405^{57}$.

En aquel ordenamiento, aparecían claramente detallados los derechos que debían llevar tanto el alguacil como sus hombres por las labores de detención de delincuentes, carcelaje de los mismos y entregas en las aldeas de la jurisdicción de Guadalajara, entre otras funciones. También se encuentran detalladas las penas que sufrían por consentir algunas irregularidades o no hacer cumplir las leyes que tenían que defender. A modo de ejemplo diremos que, por no controlar los juegos de dados, podían llegar a sufrir la pérdida del oficio y quedar por perjuros, tal como se ha visto y que nos indica que las ordenanzas de 1463 tuvieron en todas la anteriores un buen espejo donde mirarse.

Aunque la representación administrativa y ejecutiva de la justicia local la llevaban los oficiales más representativos, para las actuaciones más triviales en la aplicación de los hechos judiciales se necesitaban un conjunto de ayudantes de menor rango que actuaban como hombres de los sobredichos ayudantes. De entre

56 LOPEZ VILLALBA, idem...«e non entran en mesones nin en posadas, salvo en las plaças e mercados e lugares públicos e como han vendido se van a sus casas...», "porque no son personas que rrevuelvan rruidos, commo porque non tienen posada donde las dexar», p. 343.

57 A.M.(GU). 1H3.8a. «..E estos omes a tales que el dicho alguazil tomare que sean nombrados quales e quantos son ante los rregidores de la dicha villa...». 
todos destacan los andadores, personeros o sayones, que cooperando en las tareas presuntamente modestas de la aplicación de la justicia llevaban adelante misiones importantes como hacer emplazamientos, aplicar tormentos o ayudar en la realización de los pregones.

En el momento en que alguna persona o personas eran condenadas correspondía hacer una serie de citas o emplazamientos para que se presentase ante los jueces. Estos llamamientos aparecen como una cuestión ciertamente subjetiva y poco precisa. El compromiso de los emplazadores acababa en el momento de presentarse ante el convocado y darle la nueva junto a una cita para un día concreto, es decir, su única obligación consistía, pues, en la notificación de la convocatoria. Hay una perspectiva muy interesante desde el punto de vista del Derecho, por la cual quedaba en el arbitrio del convocado su asistencia a la cita judicial, por lo que tiene de importante en la continuación del proceso y que, por supuesto, queda fuera de la potestad del convocador. Esta cuestión daba lugar, a que una vez concluidos los tres emplazamientos que se realizaban en un tiempo pautado, la persona que no aparecía voluntariamente ante el juez, era necesario llevarla ante el mismo forzadamente por los oficiales de los alcaldes.

Por ello a veces ante la eventualidad de hacer comparecer a los emplazados ante los jueces pertinentes con situaciones de resistencia, que necesitaban de mayor perseverancia y fuerza de lo habitual, quedaba estipulado que a los hombres de los alguaciles se les diese dos maravedís, es decir, el doble que en el primer supuesto. Esto si era en la ciudad o en sus arrabales, pero cuando tenía que ir a las aldeas para atrapar y traer al encausado ante los jueces, el dinero a cobrar por los hombres estaba en función de las leguas recorridas entre el lugar donde lo encontraran y el asentamiento de la audiencia que lo hubiese convocado, a razón de cuatro maravedís la legua. El término de la ciudad de Guadalajara era muy extenso y algunas de las aldeas estaban a más de cuatro leguas, por lo que se decidió que la cantidad a percibir por estos traslados desde la distancia más alejada de la urbe fuese catorce maravedís. En ciertas ocasiones durante los traslados desde las aldeas estaban condicionados a realizar otras actividades para aprovechar los traslados, por las cuales en condiciones reglamentarias percibían los salarios completos, pero en las situaciones extraordinarias los devengos se llevaban repartidos.

Ante esta diversidad de tareas la posibilidad de obtención de los salarios de forma fraudulenta se multiplicaba y llevaba a que ciertos personeros y andadores realizasen estas operaciones sin tener orden de los oficiales encargados de dictarla, por consiguiente eran obligados a dar fe a los jurados y alguaciles sobre las personas que habían emplazado, bajo qué cargos se había realizado el llamamiento, quién o quiénes habían pedido la citación, en qué plazos debía llevarse a cabo y en qué audiencias debían presentarse. Como se puede ver debían realizar un auténtico informe acerca de la misión a desempeñar que a la vez servía de inspección para los ordenantes de la misma y de control personal de las propias actividades de los actuantes. 
Ciertamente la complejidad del oficio garantizaba una vigilancia poco efectiva, por más que ésta fuese exhaustiva, principalmente por la complicación añadida de los traslados a las aldeas, algunas bastante alejadas del centro judicial, lo cual propiciaba la codicia de los actuantes que llegaban a pedir hasta tres veces más de lo presupuestado en la pena que habían de cobrar. Esta arbitrariedad debió transformarse en una costumbre muy extendida, por ello intentaron detenerla por medio de estas ordenanzas, de ahí la dureza que se obseerva en las multas impuestas a los infractores. En la primera ocasión que eran sorprendidos intentado cobrar una prenda inexistente debían ser sancionados con sesenta maravedís que inmediatamente debían pagar y que eran destinados a la reparación de los muros, además de devolver lo cobrado impropiamente. Si no había escarmiento, la segunda vez que cometieren el delito la pena que debía recibir, además de todo lo anterior, se volvía corporal, llegando a aplicársele al trasgresor hasta sesenta azotes, pero en el supuesto improbable que tornase a hacerlo una vez más, se doblaba la pena impuesta en los primeros casos, al mismo tiempo que se le prohibía que volviese a tener oficio de ningún tipo en el concejo.

De entre los hombres que los alguaciles mantenían como ayudantes destacan los sayones o sagiones que eran encargados de las labores más sórdidas ${ }^{58}$. Como agentes ejecutivos que eran, además de otras competencias, tenían la de la ejecución de las penas corporales. En estas ordenanzas aparecen como atormentadores siempre por mandado del alcalde, por lo que cobran cada vez seis maravedís. Si el castigo a impartir era el azote público recibían por ello el doble del caso anterior, también podían ejercer como cortadores de miembros, que bien pudieran ser orejas, manos o pies, y entonces llevaban, veinticuatro maravedís y por último, como verdugos que ejecutaban las sentencias de muerte, podían, además del arancel, tomar asimismo el jubón, el camisón, las calzas y los zapatos del ajusticiado.

Todas estas actuaciones, que se han visto en el desarrollo de esta visita tanto a los oficiales mayores como menores de la justicia local, debían ser pregonadas para general conocimiento de la población que de este modo quedaba avisada de los desempeños de los ejecutores concejiles. Los derechos de pregón, que fueron regulados igualmente por estas ordenanzas, eran tan variados como las cuestiones pregonadas. Entre la lista de derechos a percibir por los pregoneros destacan los cuatro maravedís que recibían por los anuncios que se hacían para dar aviso público de las personas que habían sido denunciados ante el alcalde y de los delitos que habían cometido, para que se presentasen lo más brevemente posible ante ellos y que éstos los pudiesen tomar presos sin necesidad de ir a buscarlos. Algo

58 Según Valdeavellano el sayón era un oficial inferior de la administración de justicia y un agente ejecutivo proveniente de la administración real o señorial que en el concejo tenía la función de citar a juicio por mandato del juez, cumplir las órdenes de los magistrados municipales, prender a los malhechores, tomar prendas, actuar de ejecutores de los fallos y decisiones de los Alcaldes, entre otras. VALDEAVELLANO, L. G. de: Curso de Historia de las Instituciones españolas. De los orígenes al final de la Edad Media. Madrid, 1968, pp. 504, 505, 516, 524, 540, 544, 546, 568, y 595. 
menos, tres maravedís, obtenían por dar a conocer las cartas del rey referentes a razones civiles o criminales. Se debe remarcar que entre todos los ayudantes de la justicia el del pregonero era el oficio que menos devengos extras embolsaba por sus intervenciones, debido a que muchos de los pregones que debía echar en el transcurrir de estas actuaciones estaban tipificados por ordenanza dentro de sus obligaciones 0 atribuciones generales ${ }^{59}$. Los hombres de los alguaciles tenían en ocasiones poco definido el coto a cobrar, de tal suerte que el único postulado era, ante igual trabajo a realizar cobrar la mitad que sus jefes.

Todos estos oficiales, en el transcurso de su actividad laboral, requerían el apoyo expreso de un oficial capitular, el escribano de concejo, que poseía la llave de la memoria de lo acontecido en el ámbito local. Aunque no es el motivo de estas páginas, se ha de decir que los escribanos de concejo fueron imprescindibles en la vida administrativa del mismo, ya que fundamentaron su principal labor en dar testimonio de lo acontecido en las reuniones del cabildo y en preparar la variada documentación que el concejo necesitaba para comunicarse, dar licencias, ordenar y revisar cuestiones de todo tipo. Además, custodiaban toda la documentación emanada y recibida por el concejo en aras de su actividad, principalmente aquellos diplomas que otorgaban a la ciudad o villa sus beneficios y privilegios señoriales o reales ${ }^{60}$.

\section{CONCLUSIONES}

Las viejas civitates romanas perdieron toda su pujanza después del descalabro del imperio en el siglo $\mathrm{V}$ hasta entrar en un lento declive que aún arrastrarían en los primeros siglos medievales. Dicha decadencia se fue superando con las distintas renovaciones que sufrieron hasta cambiar su estructura urbana, su orientación económica y su gobierno, muchas veces quasi soberano; de tal suerte que, a pesar de las revueltas sociales y de las intervenciones señoriales y reales, consiguieron llegar a la Baja Edad Media transformadas en unas comunidades de población autónoma que podía ejercer su propio gobierno y su justicia privativa. Los centros de población urbanos además de lugares de convivencia fueron transformándose a lo largo del tiempo en entes políticos y administrativos. Muchos fueron los factores que coadyuvaron a esta sedimentación administrativa y de gobierno que nació en las iniciales asambleas de vecinos. Aquellos embrionarios conjuntos

59 LÓPEZ VILLALBA, «Estudio y transcripción de las ordenanzas..., «Otrosý que non lleven derecho alguno de las ordenanças e cosas que ordenaran en el ayuntamiento de la ciudad por mandado de los regidores que se mandasen pregonar» "Otrosy que las cartas e mandado del rey, nuestro señor, que enbía a las çibdades e villas sobre algunas cosas que su alteza manda fazer e guardar e que se pregonen, que non lleve derecho alguno, salvo sy fuere a pedimiento de persona syngular».

60 La labor del escribano de concejo se encuentra plenamente analizada en trabajos de gran enjundia de los que destacamos los de: ARRIBAS ARRANZ, F.: «Los escribanos públicos en Castilla durante el siglo XV». En Centenario de la Ley del Notariado. Estudios Históricos, I (Madrid, 1964), pp. 169-260; y el clásico de Esteban CORRAL GARCÍA: El escribano de Concejo en la Corona de Castilla (siglos XI al XVIII). Burgos, 1987. 
de personas encerrados entre murallas y con unas normas apenas esbozadas hubieron de ganarse las jurisdicciones que les permitieron tener intervenciones sobre los asuntos más importantes. Para ello se nombraron unos oficiales que controlaban una vida urbana cada vez más desarrollada y fueron el germen de los primeros magistrados locales, llamados jueces, que eran refrendados por las elecciones vecinales. Durante la Alta Edad Media existió una ausencia de diferenciación entre ciertas cuestiones políticas y administrativas. Algunos autores han puesto de manifiesto el sentido de la función de justicia en los primeros siglos del medievo como parte de la posesión regia de todas las funciones de gobierno, sin delimitaciones clarificadas institucionalmente, y con la evidente indefinición que esto comporta, lo que propició la creación de normas autonómicas de gobierno concejil61

Desde mediados del siglo XIII hay un cambio radical que aumentará paulatinamente debido a la política centralista de Alfonso XI y que conllevó la creación de una nómina de oficiales al servicio de la Corona. Estos oficiales, entre otras muchas cosas, estaban encargados de impartir la justicia en los asuntos concernientes a la vida local, gracias a lo cual manejaban muchas de las claves en cuestión de gobierno. Fue un proceso largo que suscitó resistencias en muchas partes, pero que se fue asentando con las diferentes intervenciones regias que permitieron que nuevos tipos de oficiales se fueran sumando a la lucha que desde la corona se libraba para el control político absoluto. La apuesta, que aunque fuerte resultó muy sagaz, era lograr la autoridad sobre las poblaciones por medio del dominio de los diferentes niveles de aplicación de la justicia. De modo que en muchas ocasiones, sobre todo, tal como se ha visto, a partir de Alfonso XI y su Ordenamiento de Alcalá de 1348, la intervención judicial de los monarcas dentro de las poblaciones se transformó en una actividad cotidiana. Por encima de los diferentes oficiales locales dependientes de la autoridad concejil o real se impuso la figura del corregidor que acabará prevaleciendo como el verdadero factótum de la justicia regia en las localidades castellanas ${ }^{62}$. El corregidor fue, allá donde pudo ejercer su

61 Son partidarios de esta teoría García Gallo, Roldán Verdejo y otros. No deja de existir un grupo de autores contrarios a la misma, comandados por Gallego Anabitarte, que opinan que ya en los inicios de la Baja Edad Media existe una irrefutable distinción entre lo gubernativo y lo judicial. GARCÍA GALLO, «La división de las competencias administrativas en España en la Edad Moderna. En Actas del II Symposium de Historia de la Administración. Alcalá de Henares, 1969. GARCIA VERDEJO, R.: Los jueces de la monarquía absoluta. Universidad de La Laguna, 1989. GALLEGO ANABITARTE, «Administración y Jueces. Contencioso y Gubernativo. Revista General de Legislación y Jurisprudencia. LXIII, 231, (1971), pp. 235-248.

62 No se deberían acometer los estudios sobre los regimientos sin acudir a los estudios clásicos citados en la nota $n .^{\circ} 10$ de este trabajo además de multitud de trabajos referidos a bibliografía local mucho más específicos pero de indudable interés que resultarían imposibles de enumerar, pero de los que se citarán algunos: GIBERT y SÁNCHEZ DE LA VEGA, R.: El concejo de Madrid: su organización en los siglos XII al XV. Madrid, 1949. GONZÁLEZ JIMÉNEZ, M.: El concejo de Carmona a fines de la Edad Media (1464-1523). Sevilla, 1973. DÍAZ DE DURANA, J.R.: Vitoria a fines de la Edad Media (1428-1476). Vitoria, 1984. ASENJO GONZÁLEZ, M.: Segovia, la ciudad y su tierra a fines del Medievo. Segovia, 1986. MORENO NUÑEZ, J.I.: Ávila y su tierra en la Baja Edad Media (siglos XIII-XV). Valladolid, 1992. LÓPEZ NEVOT, J.A.: La organización institucional del municipio de Granada durante el siglo XVI. Granada, 1994. VAL VALDIVIESO, M.I. del.: «Medina del Campo en la época de los Reyes Católicos». En Historia de Medina del Campo y su tierra. I (1986), Medina del Campo, pp. 308-311. 
mandato a plenitud, la autoridad judicial por excelencia, de tal suerte que los alcaldes quedaron supeditados a sus órdenes y que a su vez se ayudaron de los alguaciles y de una suerte heterogénea de oficiales menores.

Visto en las páginas anteriores el dilatado abanico de oficiales que desarrollaba su actividad en el manejo de la justicia local, se ha podido seguir y concretar la forma y cantidad que adquirían sus notorias intervenciones en el tratamiento de los procesos penales y las retribuciones que conseguían por las mismas comenzando por las diligencias que consumaban la apertura del expediente judicial y el resto de cada una de dichas intervenciones con los correspondientes salarios que recibían por ellas. Llegados a este punto, no es necesario advertir lo verdaderamente complejo que resulta generalizar acerca de una estructura jurisdiccional única y normalizada para todas las poblaciones bajomedievales de Castilla dado el abigarrado sistema de oficiales implicados, y más aún, conocida la aplicación que de dicha justicia hacían aquella pléyade de empleados en oficios tan complejos en las diferentes poblaciones. Además, dadas las variadas acepciones y competencias que se pueden encontrar sobre dichos oficiales concejiles a lo largo de los siglos medievales es prudente acercarse a la cuestión desde la evidencia del hecho concreto estudiado ${ }^{63}$.

Los alguaciles y sus hombres, al igual que los alcaldes, una vez finalizado su mandato se exponían ante los regidores para recibir las quejas que contra ellos tuviesen todas aquellas personas, que se considerasen agraviadas durante dicho periodo. Se obligaban, por último, en dicha exposición a satisfacer lo que hubieran defraudado. En caso contrario, eran sometidos a diversas penas por los regidores, que de este modo vuelven a demostrar su preeminencia sobre todos los oficiales del concejo. Lo que se manifiesta en este procedimiento queda bastante cercano a los juicios de residencia que tenían los oficiales reales, principalmente los corregidores. La cuestión de la residencia es fundamental en el desarrollo de múltiples cuestiones de gobierno de los municipios y aparece tempranamente en las Partidas, aunque sin hacer clara alusión a esta definición. Pero no será hasta la etapa que inaugura Alfonso XI cuando realmente haya una reglamentación más concreta, pero que en ningún caso conseguirá efectividad al menos hasta el reinado de los Reyes Católicos donde se insertará en los Capítulos para Corregidores de 1500. Así pues aunque la residencia se aplicó más en unos periodos que en

63 Siguiendo a Regina Polo podemos reunirlos por las funciones que llevaban a cabo: Oficiales de justicia, grupo de los relacionados con la administración de justicia. Destacan los alcaldes y alguaciles, así como los merinos y prebostes. Oficiales de gobierno concejil, todos aquellos cuya obligación pasaba por el control del cumplimiento de la normativa municipal en todas sus vertientes. La actividad se podía desarrollar en la ciudad o villa o en la Tierra, es decir, en el alfoz circundante a la urbe. Destacan los veedores, los fieles y los almotacenes. Oficios de hacienda, aquellos relacionados con el control y asesoramiento de las finanzas del concejo. Destacan los mayordomos y contadores. Oficios de representación, serían aquellos que tenían que ver con las cuestiones jurídicas y de representación del concejo en pleitos y asuntos diversos. Se pueden citar los letrados y procuradores. Oficios militares, algunos oficiales desempeñaban labores preventivas de defensa del concejo o de los emplazamientos militares dentro de los mismos: plazas fuertes, torres defensivas o alcázares. Son los alcaides y alféreces. POLO MARTÍN, R.: op. cit., pp. 365-366. 
otros queda por demostrar la eficacia que pudo tener. Es por lo mismo que resulta sorprendente que en estas ordenanzas de 1463, aún lejanas a los tiempos más rigurosos que han de venir para los municipios, se haga una revisión de las actuaciones de los oficiales de justicia para que se les exija respuesta a las intervenciones poco afortunadas que hubiese podido tener.

A modo de conclusión final se pueden hacer las siguientes preguntas: ¿Por qué tanta insistencia normativa para la fijación de los derechos? y ¿Cómo se financiaba la justicia local?

Respecto a la primera de las cuestiones se observa que dentro de la actividad municipal existe una prolongación de las funciones administrativas de los órganos superiores de gobierno, tales como la Corte, que se reflejan en los hábitos burócratas del municipio. Este fenómeno es fácil de distinguir entre otros aspectos, en la documentación que emana del concejo y que siempre ha de ir detrás de la proveniente de la Cancillería Real, que, de algún modo, junto al resto de las cancillerías solemnes, fijarán las tipologías universales. Esta misma metodología continuista se sigue en las labores judiciales locales que siguen de cerca los tratamientos que sobre justicia se llevan a cabo en los tribunales superiores. Por ello se repiten muchos de los postulados referidos al desempeño de los oficios y, en su caso, de los procedimientos sancionadores.

Los jueces, o aquellas personas que ejercían sus funciones en el concejo, mantenían un conjunto de compromisos que en la generalidad de los casos era de mayor relevancia respecto al resto de los oficiales locales e incluso reales. El uso del oficio judicial se manifestaba complicado porque el desarrollo de su actividad era proclive al incumplimiento, o al menos a la dejación o laxitud en sus funciones, a veces involuntaria ante tanta prohibición, prevención o incompatibilidades. Si bien es cierto que desde la más temprana legislación judicial, principalmente las Partidas, se muestra a una serie de oficiales locales que imparten justicia y que reciben un bien ganado premio por el correcto cumplimiento del deber; existe un mayor número de fuentes que nos hablan de sanciones que pueden recibir si no cumplen adecuadamente las funciones, llegando en el caso de los oficiales reales a ser castigados con penas muy duras que los apartan del oficio. En el supuesto analizado, referente a una ciudad concreta no se encuentra tanto la disposición generalizada sino que se tiende a castigar con concreción los incumplimientos más delimitados.

Entre los hechos sancionables más significativos dentro del espacio de aplicación de la justicia local destacan las sanciones por exceso en el cobro de los derechos o por prevaricación y aceptación de dádivas ${ }^{64}$. El incumplimiento del sentido de la función asignada por una merced real además del consentimiento implícito

${ }^{64}$ Según se puede observar en una de las disposiciones de las ordenanzas estudiadas: LÓPEZ VILLALBA, "Estudio y transcripción de las ordenanzas»...: «E porque algunas vezes, diz que algunos juezes o alguaziles que dieron lugar e liçençia para jugar en algunas casas a los dados secretamente, porque les davan parte del tablaje que se sacava, lo qual es en deserviçio de Dios e del dicho señor rrey, por lo aver mandado vedar e así mismo daño a los vezinos e moradores de esta çibdad», p. 342. 
del concejo para el ejercicio del empleo se debe entender como falta de servicio a la Corona, por lo cual llevará acompañada la pena real65. Por otro lado se destaca la pena impuesta por quebrantamiento de juramento que estará acompañada siempre por la pérdida o privación del oficio, sobre todo a partir de la llamada Pragmática de Guadalajara de 1436 que entre otras cosas dejará tipificada dicha sanción ${ }^{66}$.

En resumen, los permanentes abusos, resultantes de normativas poco clarificadoras o de la inexistencia de estas, dieron lugar a continuos sobresaltos en los pobladores de las ciudades que veían como los detentadores de los oficios judiciales se aprovechaban de su status y forzaban situaciones arbitrarias en el transcurso de los procesos judiciales por el cobro inmoderado de sus derechos. No sólo los oficiales de menor rango dentro de la estructura judicial local acudían a estas prácticas, sino que hasta las esferas más altas se veían proclives al exceso y con ello a causar graves perjuicios a los moradores de sus poblaciones.

Opina Roldán Verdejo que había dos graves males que minaban la base del sistema. El primero estaba en la gran cantidad de oficiales menores que recibían su salario por medio de las tasas correspondientes a los trabajos realizados en la actuación de la justicia. Cada uno de los hechos llevados a cabo en el desarrollo del proceso judicial tenía un honorario adscrito, de tal modo que la labor administrativa que se hacía cargo de las liquidaciones de los derechos de los oficiales se complicaba hasta niveles inusitados por la enormidad de los asuntos a liquidar económicamente. La segunda de los lacras de este método, y aún más grave, era el terrible desorden contable de la Cámara real, lo cual evitaba que muchas de las penas destinadas a engrosar los fondos de la misma se perdieran por la ineficacia del sistema ${ }^{67}$.

La segunda respuesta ha de contestar al origen del monetario corriente con que se costeaban los aranceles que percibían los oficiales. En primer lugar se debe puntualizar que los salarios que percibían los magistrados superiores, es decir, los que impartían la justicia en los tribunales colegiados se encontraban alejados de los que recibían los oficiales concejiles objeto de este estudio y que desarrollaban su labor en las entidades locales. La disparidad procede sobre todo del lugar de donde emana el dinero que perciben como salario. Los corregidores por el hecho de ser nombrados por la Corona deberían percibir el sueldo de las arcas reales, mientras que aquellas otras justicias locales, aparentemente de menor rango, ingresan sus soldadas de los municipios en los que desarrollan su trabajo. Pero en

65 Sobre esta cuestión de la merced regia es necesario revisar publicaciones tan interesantes como clarificadoras. DIOS, S. de: Gracia, merced y patronazgo real: La Camara de Castilla entre 1474-1530. Madrid. 1993; y NIETO SORIA, J.M.: «El poderío real absoluto» de Olmedo (1445) a Ocaña(1469): la monarquía como conflicto. En la España medieval, 21 (1998), pp. 191-ss.

66 LÓPEZ VILLALBA, «Estudio y transcripción de las ordenanzas..., : «E por la terçera vez que pierda el ofiçio e quede por perjuro e infamias, pues juró de guardar estas hordenanças e las quebrantó» $\mathrm{p}$. 342.

67 ROLDÁN VERDEJO, Los Jueces de la monarquía ..., p. 172. 
contra de lo que dicta la lógica la Corona aprovechó para constreñir, aún más, a las ciudades obligándoles a sufragar con sus propios fondos todos estos gastos. De este modo, tanto el corregidor como el resto de los oficiales municipales de justicia cobraban de las arcas municipales, lo cual supuso en múltiples ocasiones las airadas protestas en las Cortes de las villas y ciudades que solicitaban que el corregidor recibiera sus haberes de la Corona puesto que ésta lo había nombrado. Después de una agria y larga lucha por conseguir redimirse de esta carga, las poblaciones hubieron de reconocer su fracaso ante la normativa emanada por los Reyes Católicos y aceptar esta situación durante toda la Edad Moderna. Las formas de estipendio se resumían, por lo tanto, en el binomio salario-arancel, sistema propio de muchos de los oficios públicos medievales. No resulta sencillo ponderar qué cantidad de lo recibido por su trabajo correspondería a cada una de las formas de obtención del pago. Aunque se puede aventurar, después de lo expuesto y de la revisión de las tasas recogidas en las ordenanzas estudiadas, que una buena parte de lo remunerado estaría bajo la forma de arancel e incluso con la ayuda de algunas prebendas que no se recibían en numerario ${ }^{68}$.

Los procedimientos de cobro estarían muy próximos para todos los restantes oficiales de la justicia municipal y se basarían igualmente en los dos sistemas de ingreso. El resultado finalmente generalizado se fundamentaba en un método reiterado del mismo modo por parte de los distintos gobiernos concejiles, por medio del cual una vez establecido el salario fijo, quedaba la posterior normalización de los derechos arancelarios. Dichos derechos eran muy complejos de controlar porque, como se ha visto en el desarrollo de este trabajo, cobrados de uno en uno apenas resultaban menudencias dinerarias, pero finalmente resultaban muchos y muy variados por lo que su seguimiento se concluía en una laberíntica fiscalización de muy difícil vigilancia desde el gobierno del concejo correspondiente y aún más desde la Corona.

Como es manifiesto constatar para los siglos posteriores, el camino seguido durante la Edad Moderna con respecto a la política regia en los municipios significa una clara continuación del intervencionismo bajomedieval. Se puede ver, consiguientemente, como la organización jurídico-institucional del municipio tardomedieval ha de presentar para su mantenimiento un extenso conjunto de oficiales que aumentó proporcionalmente al deseo de poder real sobre las ciudades. Dicho intento, comenzado siglos antes, fue apoyado en muchas ocasiones por los grupos menos notables de las citadas urbes que vieron en aquel dominio real una vía de escape al despotismo de los privilegiados. Tal vez en aquel escenario de potestad absolutista, los pecheros pudieron pensar que estaban más cerca de una partici-

68 De todas formas aunque en los Capítulos de 1500 se reconocía el derecho al cobro en la forma de arbitrio, se les rogaba encarecidamente que no se excediesen en ellos. Roldán Verdejo es de la opinión que la mala conciencia creada en los monarcas a raíz del mantenimiento de los corregidores por las ciudades que los albergaban y las correspondientes quejas de las mismas, hizo que se vigilasen estrechamente los abusos en los cobros de los derechos de los corregidores y sus asistentes que superan con amplitud las disposiciones dictadas para otros oficiales. ROLDẢN VERDEJO, idem, p. 167. 
pación activa en los procesos de reforma institucional. Pero sólo tal vez, porque, si bien el desarrollo de la intervención monárquica en los municipios se hizo con la ayuda de los colectivos pecheros, su desorganización y falta de preparación, llevó a los reyes a buscar el apoyo de la baja nobleza. Los grupos de caballeros, aunque claramente desde circunstancias determinadas para cada ciudad, supieron integrarse al nuevo proyecto y desde una imaginativa y equilibrada integración clientelar reyes-señores pudieron caminar lentamente hacia el control absoluto de los oficios locales, especialmente los de justicia ${ }^{69}$.

69 Para una revisión novedosa de los conflictos entre pecheros y señores en Guadalajara, se debe acudir a SÁNCHEZ LEÓN, P.: Absolutismo y comunidad. Los orígenes sociales de la guerra de los comuneros de Castilla. Madrid, 1998. 